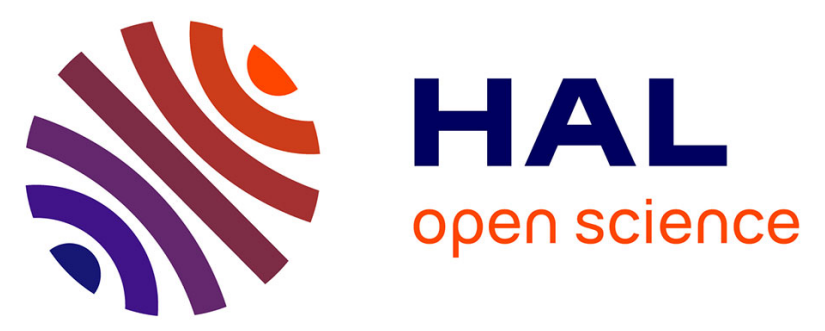

\title{
Le Capitolium de Tolosa? Les fouilles du parking Esquirol: premiers résultats et essai d'interprétation
} Jean-Charles Arramond, Jean-Luc Boudartchouk, Laurent Grimbert, Laurent Llech, Henri Molet, Isabelle Rodet-Belarbi

\section{- To cite this version:}

Jean-Charles Arramond, Jean-Luc Boudartchouk, Laurent Grimbert, Laurent Llech, Henri Molet, et al.. Le Capitolium de Tolosa? Les fouilles du parking Esquirol: premiers résultats et essai d'interprétation. Gallia - Archéologie de la France antique, 1997, 54, pp.203-238. 10.3406/galia.1997.2997 . hal-01901263

\section{HAL Id: hal-01901263 \\ https://hal.science/hal-01901263}

Submitted on 16 Jan 2020

HAL is a multi-disciplinary open access archive for the deposit and dissemination of scientific research documents, whether they are published or not. The documents may come from teaching and research institutions in France or abroad, or from public or private research centers.
L'archive ouverte pluridisciplinaire HAL, est destinée au dépôt et à la diffusion de documents scientifiques de niveau recherche, publiés ou non, émanant des établissements d'enseignement et de recherche français ou étrangers, des laboratoires publics ou privés.

\section{(ㅇ)(1) $\$$}

Distributed under a Creative Commons Attribution - NonCommercial - NoDerivatives| 4.0 


\title{
LE CAPITOLIUM DE TOLOSA?
}

\author{
Les fouilles du parking Esquirol \\ Premiers résultats et essai d'interprétation
}

\author{
Jean-Charles ArRamond* et Jean-Luc BoudarTchouk* \\ avec la collaboration de Laurent GRIMBERT, Laurent LIECH, \\ Henri MOLET et Isabelle RODET-BELARBI
}

Mots-clés. Toulouse, Cappitole, temple, Jupiter, forum, culte public, cardo, area, christianisation, martyre.

Key-words. Toulouse, (apitolium, temple, Jupiter, forum, public unorship, cardo, area, christianizalion, martyr.

Résumé. Les fouilles archéologiques de sauvetage menées en 1992-1993 à l'occasion de la construction d'un parking souterrain place Eisquirol à Toulouse ont permis la mise au jour du sanctuaire majeur du for um de Tolosa. Il s'agit d'un temple de type italique dont le podium possède une largenur reconnue de 27 m pour une longueur restituée de $35 \mathrm{~m}$. Les fondations de l'escalier momumental du temple ont pu être intégralement observées, ainsi qu'une partie de larea et de l'aile orientale du portique entourant l'ensemble momumental. L.es données de terrain confrontées à l'élude des sources historiques nous permettent de penser qu'il s'agit des zestiges du Capitolium de la cité antique, édifié zraisemblablement durant la seconde moitié du I" s. de notre ère el détruit zers l'an 400. Une église a ensuite été édifiée dans les ruines du podium, sans doute durant la seconde moitié du VT s. Cette dernière perpétue le souvenir du martyre de l'évếque Salurnin, mort sur les marches du Capitolium en 250.

\begin{abstract}
Archaeological excavations made in 1992-1993 before building an underground car park on Esquirol place in Toulouse brought the greatest sanctuary of the forum to light. It is an Italic temple with a podium which is $27 \mathrm{~m}$ wide and $35 \mathrm{~m}$ long. The foundations of the monumental stairase of this temple zuere entively found out, thus a part of the area and the pastern wing of the portico which surrounds the sanctuary.

The excatations data and historical sources lead us to think that it is the Capitolium of the ancient cily, probably built during the second half of the 1's century A.D. and destroyed circa 400 A.D. Then a church was built on the podium ruins maybe during the second half of the VIt century A.I). This church perpetrates the memory of the bishop Saturnin's martyr, deat on Capitolium stairs in 25() A.D.
\end{abstract}

Les fouilles du parking de la place Esquirol à Toulouse, qui se sont déroulées entre juin 1992 et février 1993, ont été menées par l'équipe de J.-Ch. Arramond (Association pour les Fouilles archéologiques nationales) sous le contrôle scientifique du Service régional de l'Archéologie de Midi-Pyrénées, en un point où de nombreux historiens avaient situé le forum au croisement du cardo maximus et du probable decumanus

\footnotetext{
* Base administrative AFAN Midi-Pyrénées, 7 rue (habanon, F-31200) Toulouse.
} 


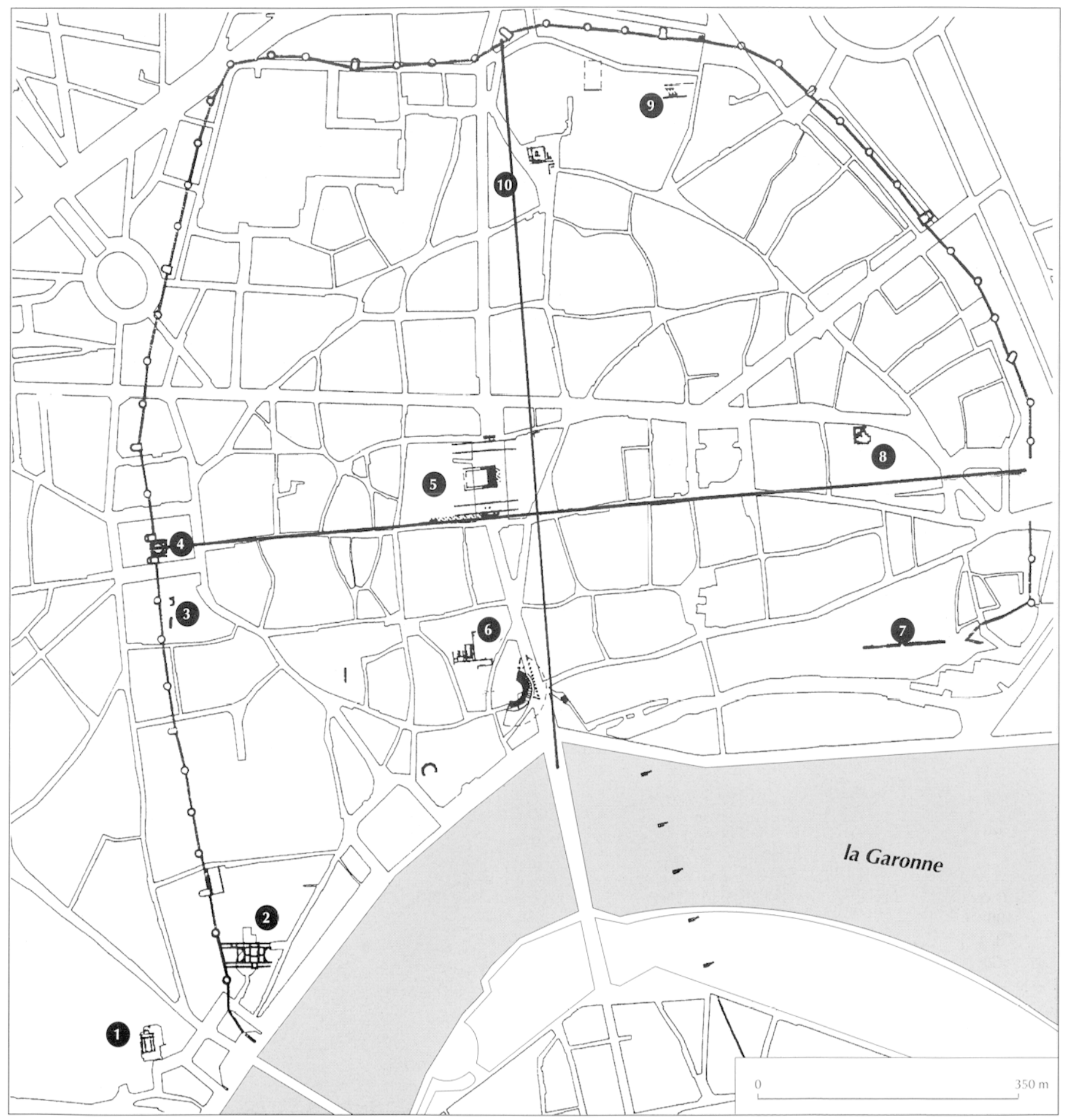

Fig. 1. Plan général avee situation des principales découvertes de Toulouse antique : 1, église Saint-Pierre-des-Ciuisines; 2, ancien hôpilal Larrey; grand bâtiment du $\mathrm{V}^{*}$ s. ; 3, rues Mirepoix/Romiguières, repentir du tracé du rempart; 4, place du Capitole, porle nord du rempart; 5 , Esquirol; 6, extension de l'Hôtel d'Assézat, la domus ; 7, rempart de l'Institul Catholique; 8, thermes de la rue du Languedoc; 9, rues SainteAnne/Saint-Jacques, extension de la Préfecture; 10, thermes privés de la place Saint-Étienne (d'après (). Cazes et la mairie de Toulouse 1988 at 1995 complété par les tracés restitués du cardo et du decumanus). 


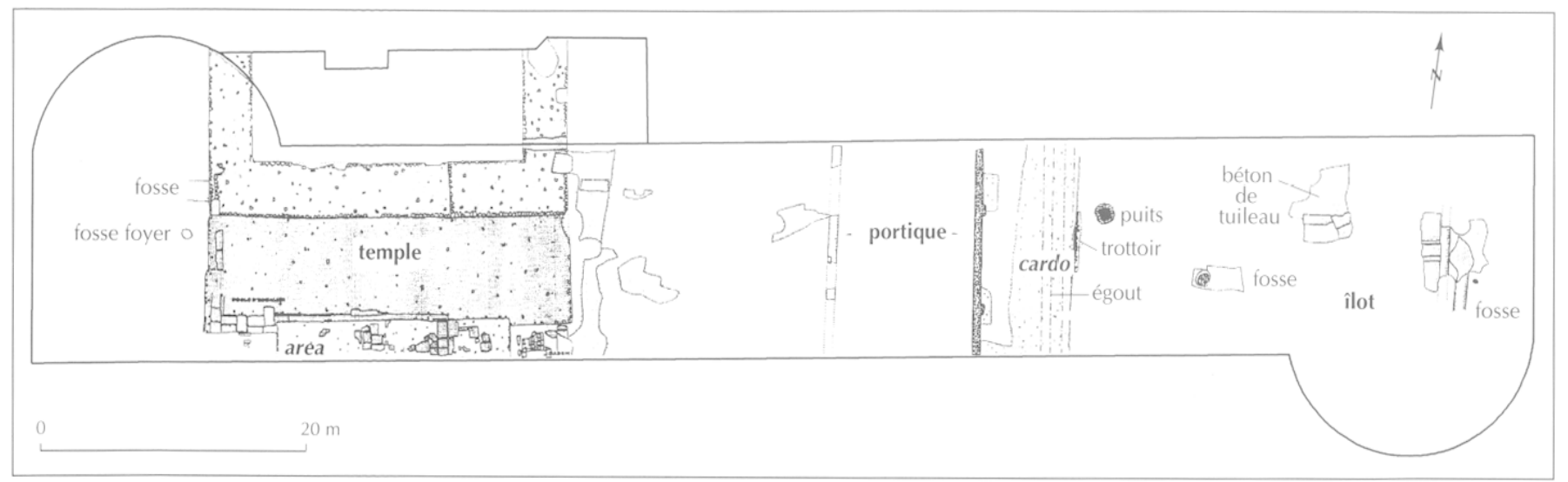

Fig. 2. Relevé des structures du Itaut-Limpire (releové L. Llech).

maximus, au coeur de la ville antique, près du théâtre ${ }^{1}$ (fig. 1).

I a campagne de fouilles a permis de mettre au jour, d'est en ouest, un îlot d'habitations antiques longé par un cardo à l'ouest duquel se développe un ensemble monumental, comprenant un portique entourant unc area. En son centre est édifié un temple de type italique de fortes dimensions (fig. 2). I es vestiges de ce sanctuaire avaient déjà été aperçus en 1862, lors du décaissement préalable à l'édification du marché métallique de la place Esquirol, par des membres de la Société archéologique du Midi de la France : « I a commission a constaté à la Pierre des substructions évidemment romaines, d'une largeur et d'une solidité extraordinaires; du reste

1. Cf. par exemple : Labrousse, 1968 , p. 428 ; Baccrabère, 1977, p. 64 ; Cazes, 1988, p. 64 ; Bedon et al., 1988 , I, p. 213 ; Filippo, 1993a.

Dès 1918, E. Martin-Chabot découvrant un texte médiéval se rapportant au Capitolium de la ville antique (cf. infra, p. 224) était amené à situer ce sanctuaire sur l'emplacement de l'actuelle place Esquirol. Mais la contribution essentielle est apportée par M. I abrousse en 1968. Au terme d'une analyse minutieuse des textes antiques tardifs mis en corrélation avec des données générales concernant l'urbanisme antique, l'auteur conclut que le Ciapitolium et peut-être le forum ont pu s'élever " place Esquirol, loin de l'église du Taur et du Capitole moderne " (Labrousse, 1968, p. 417-429). En effet certains auteurs s'appuyant sur un texte du VI* s. écrit par Venance Fortunat ( $f$. infra, p. 223) avaient situé le Capilolium extra-muros, à l'emplacement de l'église médiévale du Taur (Boudartchouk, Arramond, 1993).

A la suite de M. I abrousse l'hypothèse de la présence du Cinfitolium et du forum de Toulouse place Esquirol fut reprise par plusieurs chercheurs. Cette thèse reçut une première confirmation archéologique avec la découverte en 1990 à l'ouest de la place Esquirol d'un portique monumental (Filippo, 1993a). rien de remarquable pour l'art. [...]. Monsicur Fournalès a remarqué les substructions gallo-romaines qui ont été mises à découvert à trois mètres cinquante au-dessous du sol dans l'excavation de la place de la Picre. " (Registre des délibérations de la Société archéologique du Midi de la France, 1862, vol. III, folio 359 et 362 ).

\section{IES DONNÉES DE TERRAIN}

I.es vestiges antérieurs à la mise en place du temple et de son portique sont inexistants à l'exception d'une portion de fossé, d'orientation est-ouest, recoupéc lors de la mise en place du podium (angle sud-ouest) et creusée dans un substrat limoneux. Cé fossé a ćté curé à plusieurs reprises; son comblement naturel puis, dans un second temps, intentionnel, n'a livré que peu de mobilier. Cette structure semble appartenir à la première moitié du $\mathrm{I}^{\mathrm{cr}} \mathrm{s}$. de notre ère.

\section{PHASE DE CONSTRUCTION}

l.e niveau d'arasement général des structures antiques, déterminé par le sol de la halle métallique édifiée au XIX" s., correspond au niveau de circulation du IV" s. mis en place autour du podium. Seules les fondations de celui-ci ont donc pu ĉtre observées. 


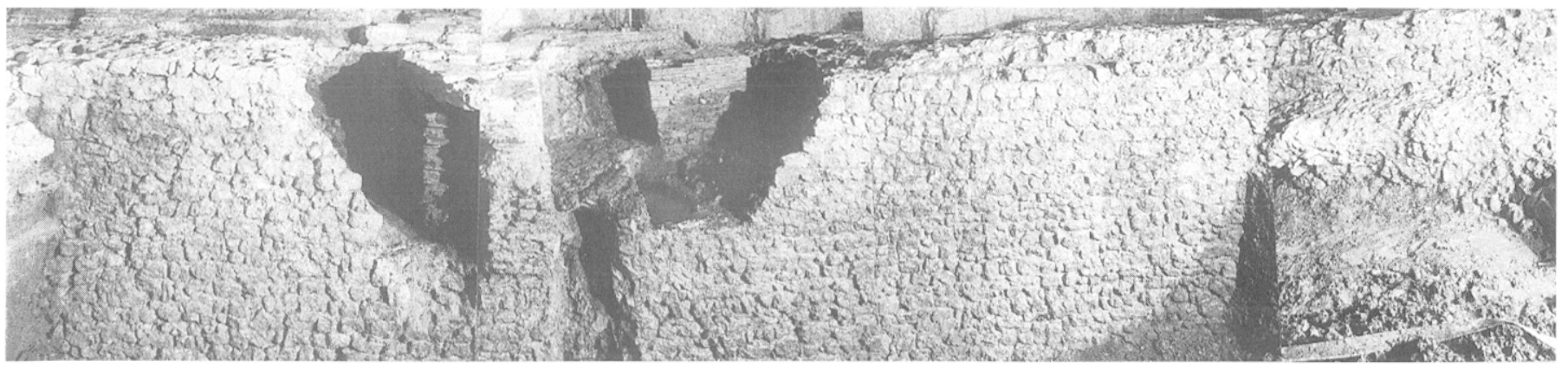

Fig. 3. Vue générale (montage) des fondations en molasse de la facade sud du podium (photo J.-M. Martin).
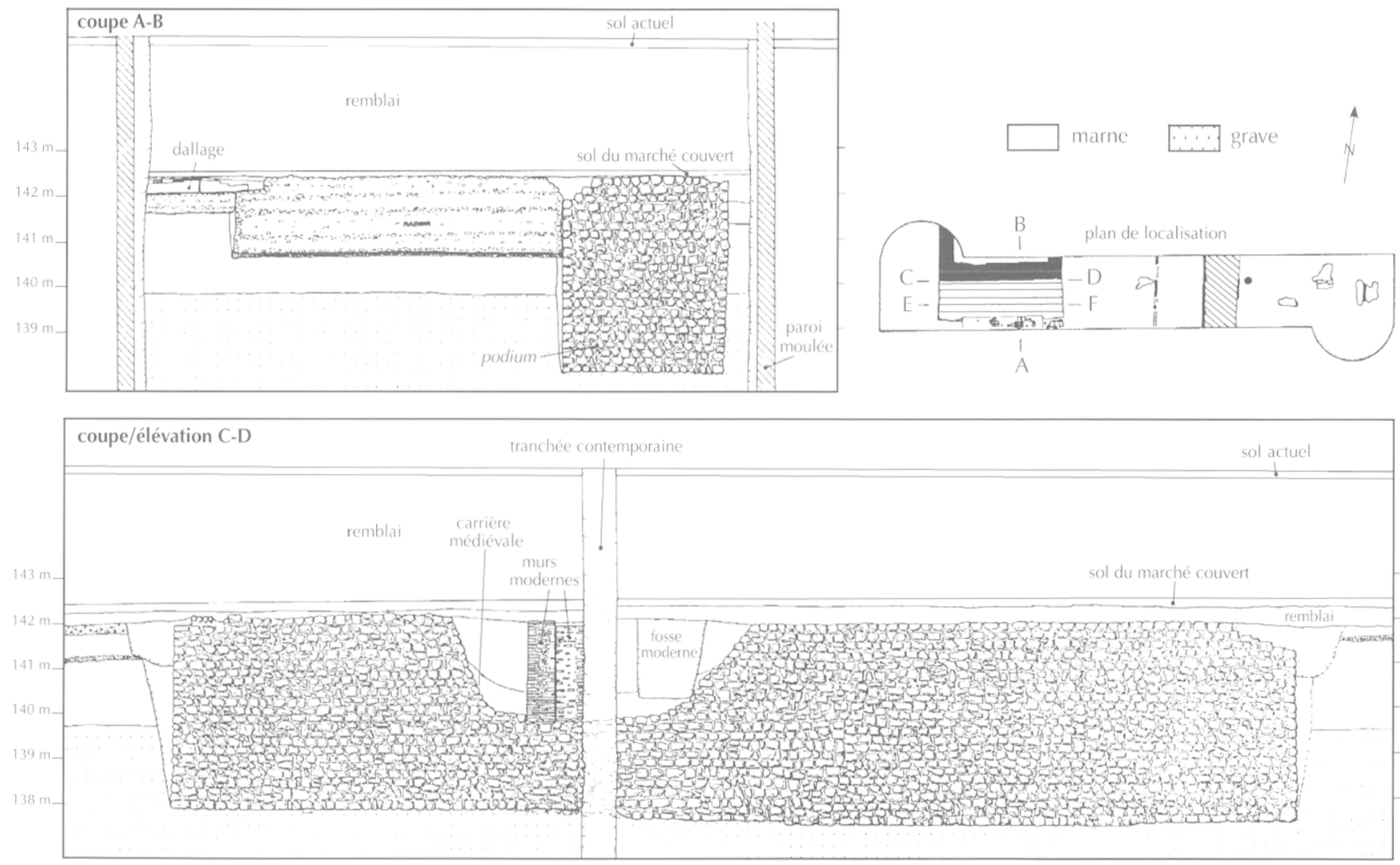

coupe E-F

ol actuel

remblai

sol du marché couver

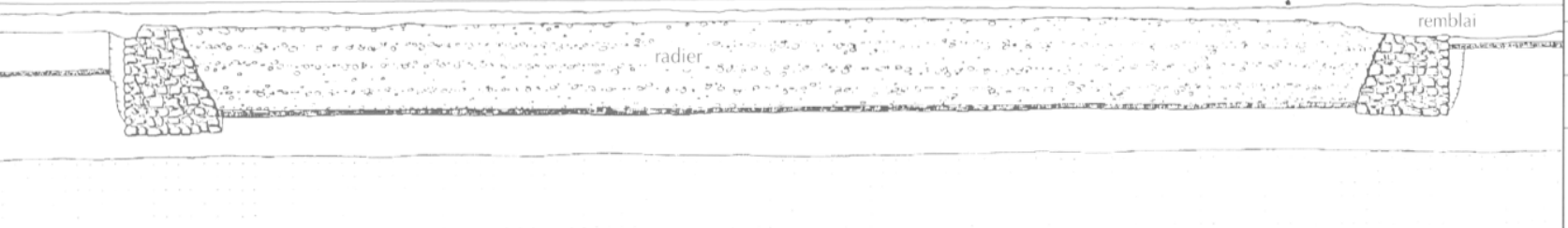

Fig. 4. Coupes straligraphiques du lemple : A-B, dallage de larea, radier de l'esacalier el soubassements de la fagade du podium ;

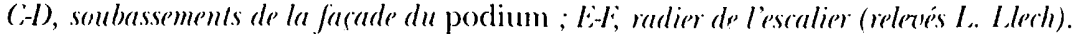




\section{LES FONDATIONS DU PODIUM}

\section{L'infrastructure du podium}

Le creusement dans la marne naturelle de la tranchèe de fondation du podium a provoqué le dégagement de nombreux déblais répartis autour de la zone de construction, piégeant une faible quantité de mobilier céramique datable du $I^{r}$ s. de notre ère.

L es fondations du podium sont implantées au contact des graves naturelles. Elles sont constituces de blocs de molasse de module variable, grossièrement équarris et liés par un mortier sableux maigre de chaux. Des témoins de cette phase de construction ont pu être retrouvés lors de la fouille de la partie correspondant à l'intérieur du podium. Il s'agit de chutes de mortier découvertes à l'aplomb du parement interne des fondations et de déchets résultant de la taille des blocs de molasse mis au jour au contact du remblaiement de marne. Ces deux éléments semblent correspondre à la première phase de construction de l'édifice, alors que le comblement interne n'est pas encore effectif.

La fouille de la partic situéc au nord-ouest du soubassement de l'escalier a également livré des traces de niveaux de construction (déchets de taille de calcaire).

Parallèlement à ces indices, quelques fosses de dimensions réduites ont été mises au jour contre le parement interne du mur oriental des fondations. Ces creusements, recoupant le niveau de marne remanié, ont livré un mobilier homogène inscrivant leur création dans la seconde moitié du I" s. de notre ère. Il est délicat de préciser davantage leur fonction : il pourrait s'agir de traces laissées par l'installation d'engins de levage destinés à la pose des blocs de l'élévation, ou bien d'échafaudages. Ces fosses sont recouvertes par la marne remaniéc ayant servi à combler l'intéricur du pronaos.

L.es fondations en molasse se développent sur une hauteur de $4,25 \mathrm{~m}$ (fig. 3 et 4). Icur épaisseur est de 3,80 m pour le mur de façade méridional supportant la colonnade et de 3,20 m pour les murs correspondant aux retours latéraux de l'édifice. Ia largeur totale de l'ensemble est de $26,90 \mathrm{~m}$. L'emprise de la fouille ne nous a pas permis d'observer la totalité de la longucur.

Ia limite septentrionale du chantier interdisait l'observation des cloisomnements pouvant diviser l'espace interne de l'édifice dans la cella, mais a permis de constater que la partie méridionale du pronaos en est dépourvuc (fig. 5). Le temple octostyle d'Hercules Victor à Tivoli, de dimensions comparables à celui de Toulouse, ne présente pas de substructions en caissons dans le pronaos (Gros, 1976, pl. XXIV). Il en est de même pour le Capitole de Virunum (Vetters, 1977, p. 315), ou le temple à trois cellae de Saguntum (Mar, Arbulo, 1990, p. 159).

Enfin, les superstructures ne sont connues qu'à travers les fragments architecturaux retrouvés dans les niveaux de démolition de la fin du IV'ou du début du Vis.

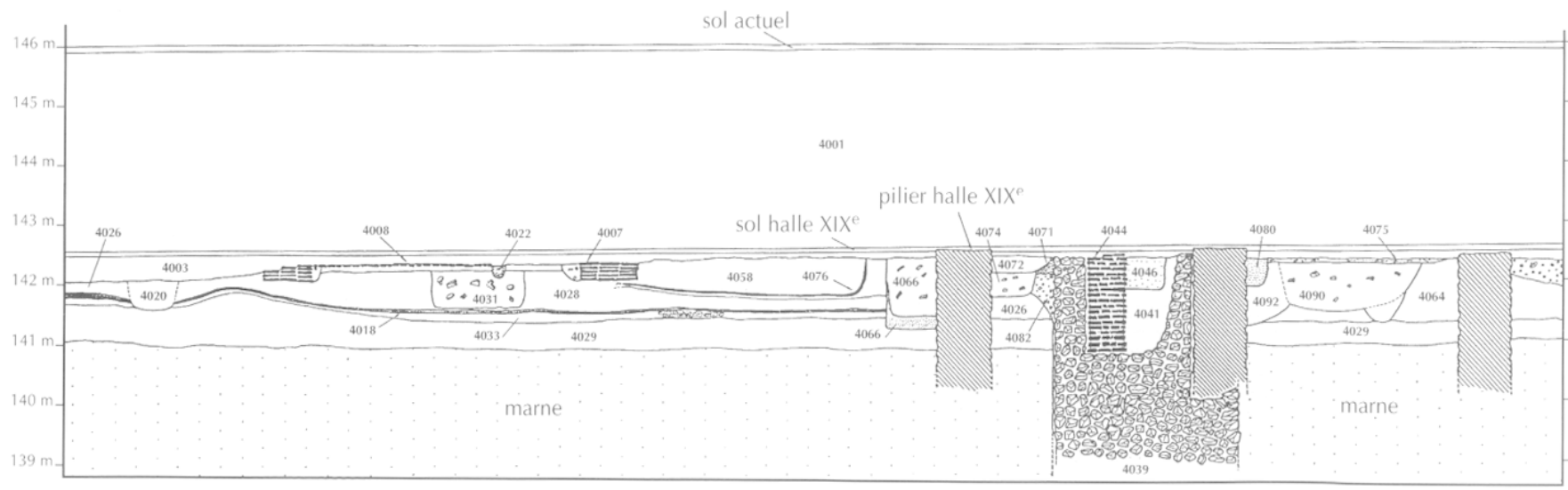

Fig. 5. Coupe stratigraphique est-ouest à l'intérieur des fondations du podium du temple, à hauteur du pronaos. Les fosses de lintiquité lardive sont localisées à l'extérieur du mur du sanctuaire, l'intérieur étant fortement perturbé par des structures du Bas Moyen $\hat{A}$ ge el modernes (relevé L. (irimbert). 


\section{Matériaux mis en œuvre pour les superstructures du temple}

I ces matériaux ayant pu être utilisés pour la réalisation du gros oeuvre de l'ćlćvation sont essentiellement la brique de revêtement striée, peut-être associée à un placage de marbre pyrénéen. I a décoration semblait, comme dans le secteur de la Curie du forum de Vérone (Cavalieri-Manasse, 1990, p. 610), assurée par un pave-

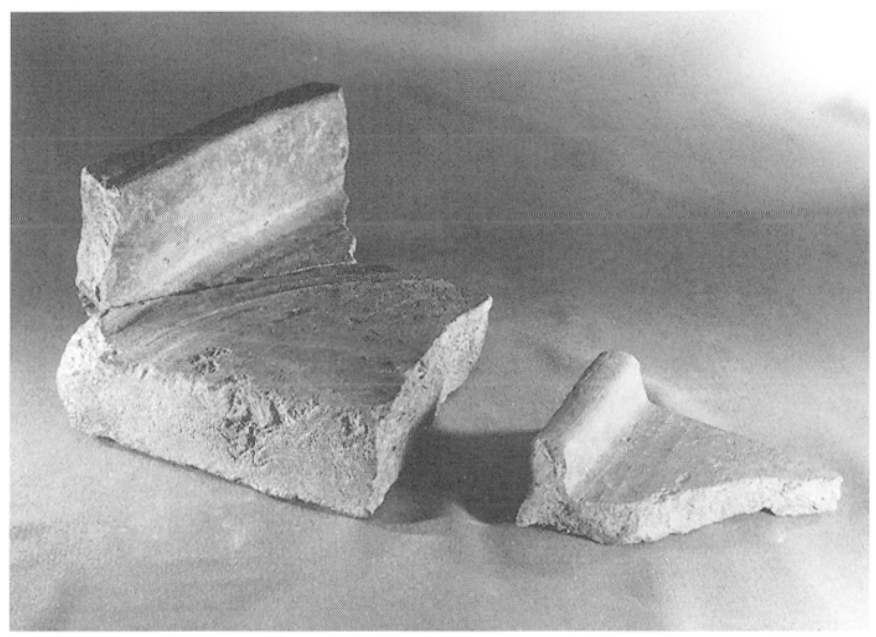

Fig. 6. Vue d'une tegula du temple (à gauche) comparée an module moyen provenant de lîlot d'habilation (à droite) (phoste I. I lech et L. (irimbert).

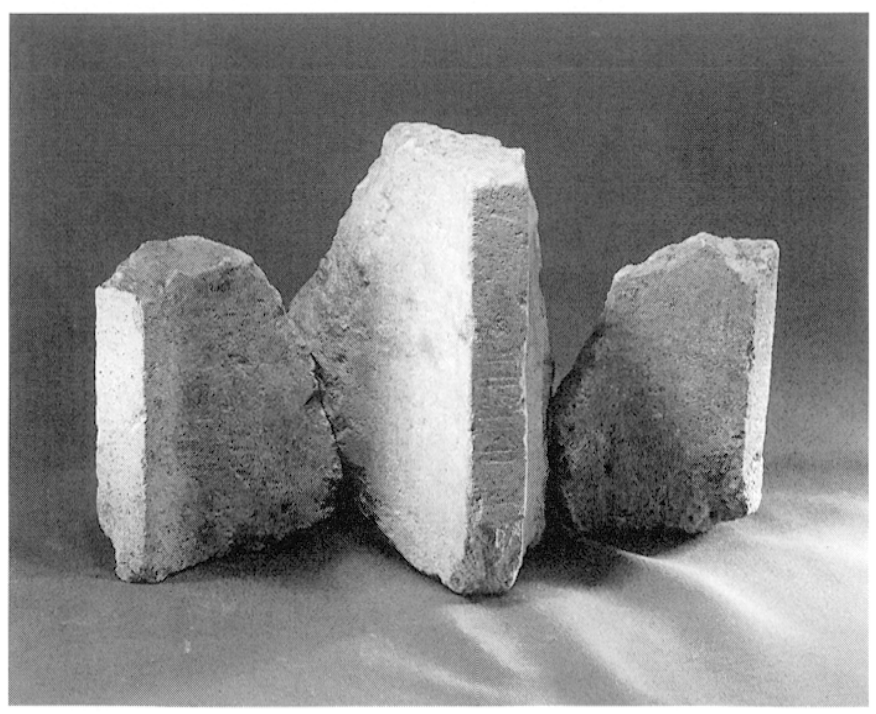

Fig. 7. Fragments de colonnes en calcaire de Belbèze troutés dans le niveau de destruction du temple, en périphérie de la fagade sud du podium (photo L. Ilech et I. (inimbert). ment en opus sectile utilisant des schistes, marbres colorés, porphyre grec vert du cap Matapan et égyptien rouge du djebel Dokkan (étude F. Veyssière). I a toiture était composée de legulae et imbrices d'un module très important (hauteur des rebords : 10 cm, ćpaisseur : 4,5 cm), spécifique au temple et à son portique (fig. 6). Le même phénomène a été constaté dans d'autres sites urbains de Gaule méridionale (Hofmann, 1975, p. 112-113). Mais ce sont surtout les fragments de colonnes qui peuvent nous apporter de précieux renseignements sur la structure générale du bâtiment. Taillées dans un calcaire coquillier, elles ne nous sont parvenues que dans un état fragmentaire découlant de leur réutilisation. I a zone externe des cannelures se prêtant peu au remploi, celles-ci, très fragmentaires, constituent l'essentiel des déchets. I a largeur des arêtes $(3 \mathrm{~cm})$ et des cannelures demi-circulaires intermédiaires $(13 \mathrm{~cm})$ autorisent à proposer un module avoisinant un diamètre de 1,20 à $1,30 \mathrm{~m}$ pour une colonne corinthienne à 24 cannelures (fig. 7). Plusicurs fragments de chapitcaux, taillés dans le calcaire coquillier de la région issu de la carrière de Belbèze (Haute-Garonne), ont été découverts dans les mêmes ensembles stratigraphiques que les arêtes des tambours de colonnes, au pied du podium. Ils appartiennent sans nul doute au même ensemble architectural ; les fragments les plus remarquables figurent des feuilles d'acanthe, un demi-fleuron (scié en vue d'un remploi), ainsi qu'un ensemble de perles et piroucttes (fig. $8, \mathrm{n}^{\circ} 1$ et 2 ). Il est donc possible de restituer au temple une colonnade d'ordre corinthien ou composite, réalisée dans un matériau local. Néanmoins certains fragments architectoniques ne se rapportent pas à la colonnade, comme un élément de pilastre cornier à décor végétal et un morceau de décor terminal de frise ou d'acrotère (fig. 8, n³ et 4).

L'emploi du calcaire de Belbèce semble donc systématique pour l'élévation du temple. Il est cependant difficile de situer précisément ces éléments en chronologie à l’intérieur du Haut-limpire (étude détaillée en cours par I). (iazes).

\section{L'ESCALIER MONUMENTAL}

I a stratigraphic observée lors de la fouille a permis de préciser la chronologie de la construction. I a majeure partie des fondations du podium était déjà construite lorsque le soubassement de l'escalier fut établi sans être chaîné à celui-ci. Il consiste en un radier de galets où 



Fig. 8. 1, demi-fleuron de chapileau monumental, en calcaire de Belbèze, provenant du temple; 2, frise de perles el pirouettes, en calcaire de Belbèze, provenant du temple; 3, fragment de feuillure monumentale, en calcaire de Belbèze, provenant du temple; 4, élément de décor terminal de frise ou d'acrotère, en calcaire de Belbèze, provenant du temple (photos musée Saint-Raymond). 
l'éude de la structure interne met en évidence trois opérations de construction. Dans un premicr temps un hérisson de galets liés à l'argile est fondé à une profondeur de $1,70 \mathrm{~m}$. Viennent ensuite deux couches de galets d'environ 0,7 in d'épaisseur, chacune noyée dans du mortier de chaux, la couche supérieure se différenciant par une moindre résistivité du mortier employé, réparti de manière inćgale. Plusieurs fragments de briques, tuiles et amphores ont été retrouvés dans ces deux niveaux (fig. 9).

Ce comblement très résistant s'inscrit à l'intéricur d'un espace délimité à l'est è à l'ouest par deux murs d'orientation nord-sud bâtis en galets. D'une longueur

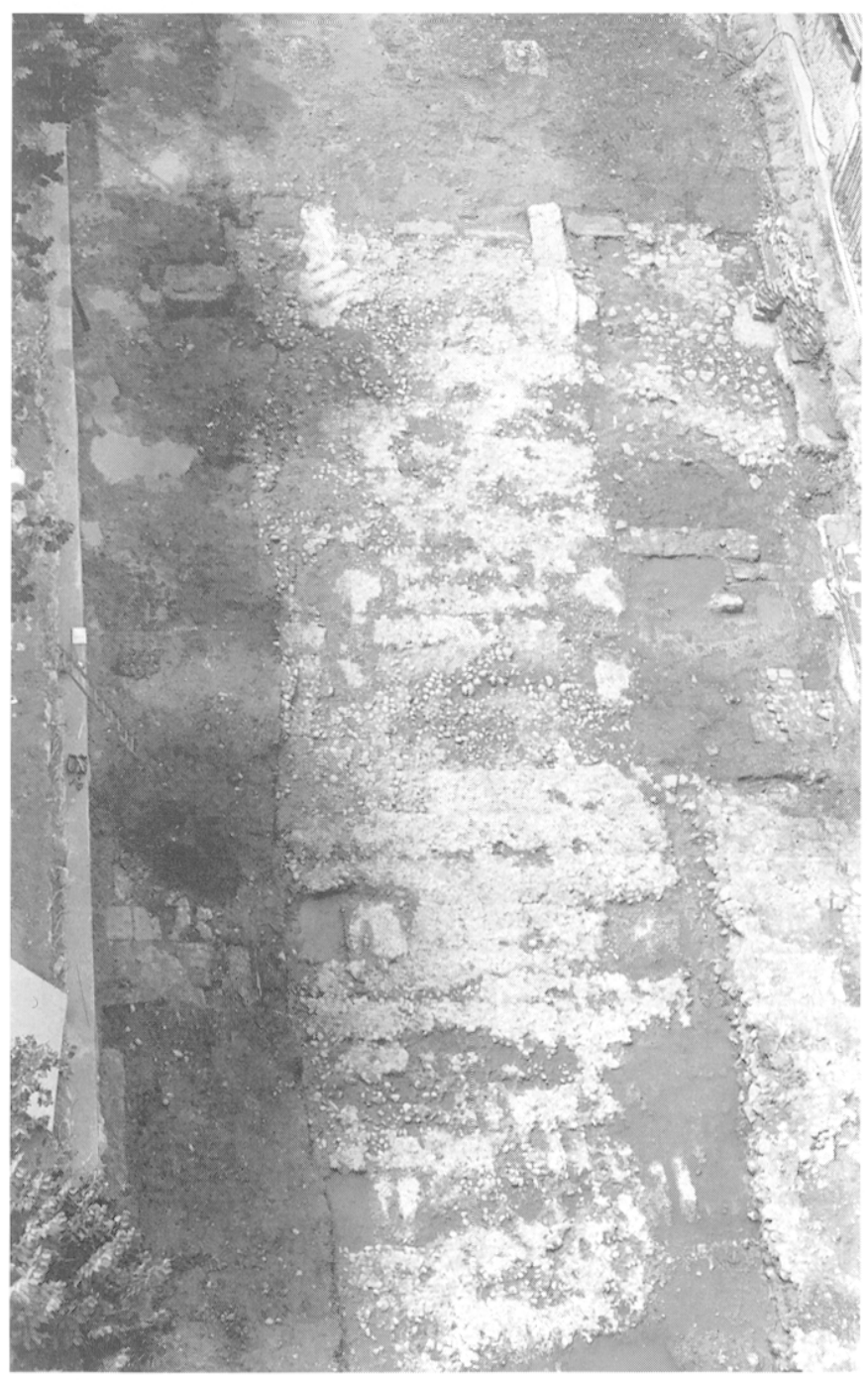

Fig. 9. Vue aévienne générale de la masonnerie de l'escalier monumental el de l'extrémilé sud du pronaos avant la fouille (photo L. L.lech). de $8 \mathrm{~m}$ pour une épaisseur moyenne de $2 \mathrm{~m}$, ces deux murs se situent exactement dans le prolongement des retours latcraux des fondations du podium (fig. 10). Leur hautcur fondéc $(1,5$ à $2 \mathrm{~m})$ est moindre que celle des murs du podlum, du fait de contraintes mécaniques moins fortes. Ils ont principalement un rôle de contention du remblaiement interne (galets et mortier) et de support de l'élévation des murs encadrant l'escalier. Ces murs servent ainsi de coffrage perdu pour le blocage. Le niveau d'arasement de l'escalier par la halle métallique du XIX"s. a conservé des traces d'assises de blocs quadrangulaires d'un module régulier, soit environ $1,20 \times 0,8 \mathrm{~m}$, notamment dans l'angle sud-ouest : nous avons donc là certainement la trace de la première assise de l'élévation ainsi que du premier degré de l'escalier (support de la plinthe).

Deux phases de mise en place ont pu être définies pour le mur occidental. La partic sud est construite essenticllement en galets liés au morticr sableux alors que la partic nord, bâtie avant la précédente et s'appuyant contre l'angle sud-ouest des fondations du podium, se compose d'un mélange de galets et de blocs de molasse (semblables à ceux utilisés pour la fondation du podium) (fig. 11). Le mur de ceinture oriental du radier est beaucoup plus homogène dans sa construction. Cette différence semble résulter davantage des aléas de l'édification du monument que d'une volonté systématique des bâtisscurs. Néanmoins le léger décrochement du pare-

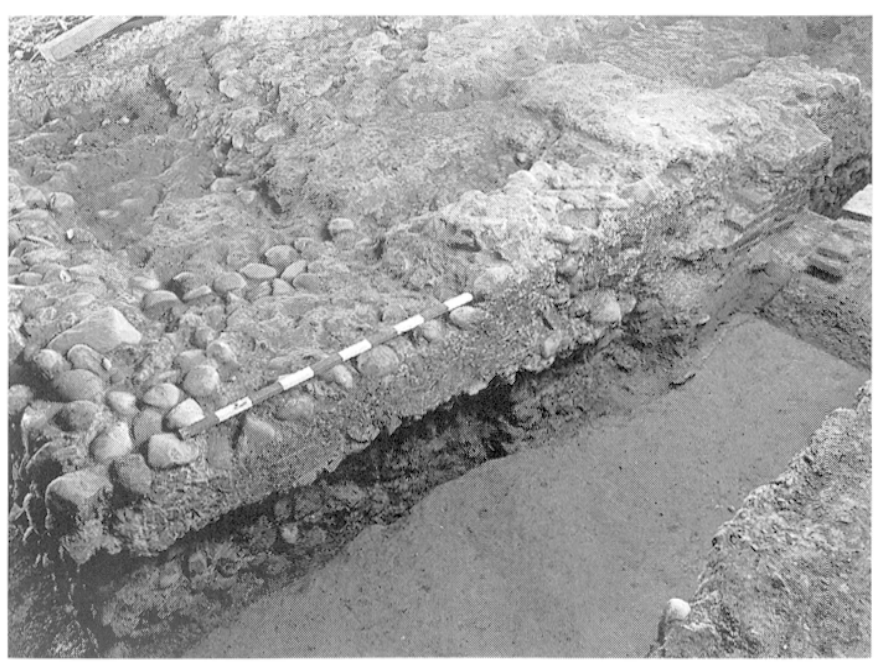

Fig. 10. Vue de l'angle sud-ouest du soubassement du podium de l'escalier momumental, longé par un canivean en briques (photo I. Cirimbert). 


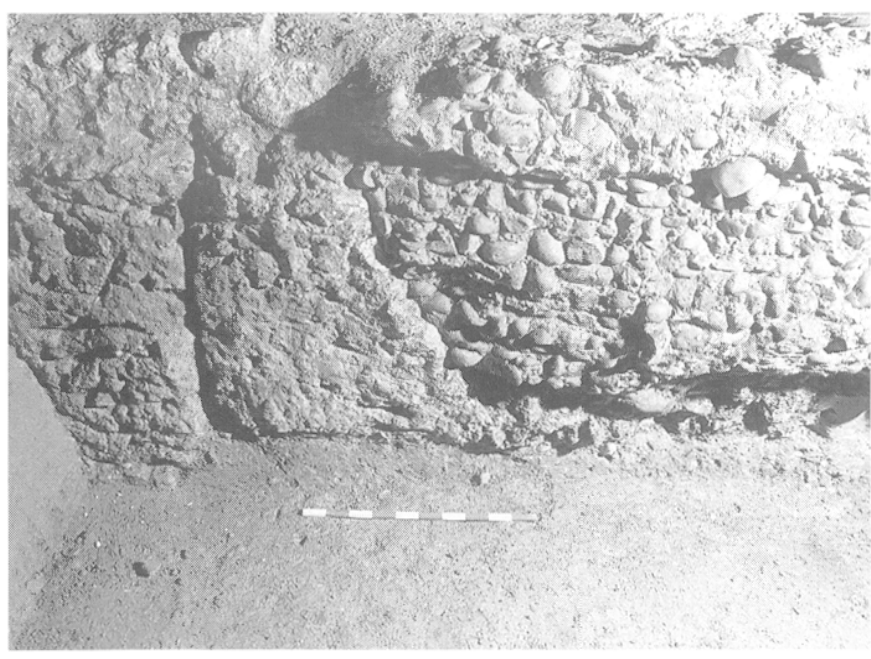

Fig. 11. Vue des reprises de construction (banchées) sur le mur ouest

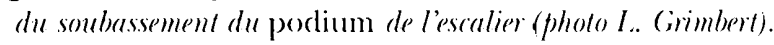

ment externe du mur occidental ainsi que sa structure différenciće pourraient traduire l'existence d'un escalier légèrement débordant en périphérie. Ainsi l'on aurait affaire à un escalier à ailes latérales, le parement sud de la partic centrale etant en retrait.

\section{L'AREA}

Au sud du radier de soubassement de l'escalier se trouve une aire dallée (fig. 12). Des dalles quadrangulaires de deux modules différents en calcaire de Belbèze, disposées en alternance, sont posées sur un radier de galets liés à l'argile de $0,40 \mathrm{~m}$ de puissance. Un muret de galets orienté nord-sud constitue peut-être un renfort pour ce radier. I.es dalles calcaires, d'une épaisseur moyenne de 0,15 à $0,20 \mathrm{~m}$, sont posées sur un lit de mortier sableux intermédiaire, très peu résistant, servant notamment à égaliser le niveau de chaque radier de galets. Ce dallage ne s'étend pas sur toute la largeur du bâtiment ; il correspond à la partie centrale de l'escalier, $5 \mathrm{~m}$ en retrait des parois de part et d'autre, dans lequel il pénètre sur une faible profondeur. Si ses limites orientales et occidentales nous sont connues par les limites de son radier, il ne nous a pas été possible de définir son extension vers le sud et de savoir s'il correspond et s'intègre à une structure plus vaste, ou s'il constitue un ensemble en lui-même comme un soubassement d'autel monumental ( $c f$. Collectif, 1991, pl. XI.I et XI. ; Coarelli,
Cajanto, 1981; Jimene\%-Sallador, 1991, p. 122). Lne structure tres semblable existe au pied de l'escalier du temple de Saint-Bertand-de-Comminges; il s'agit d'une base d'autel monumental ou de groupe statuaire (Badie et al., 1994, p. 37).

À Toulouse, des aménagements ont pu être observés à proximité de cette aire dallée. Un caniveau d'orientation est-ouest, bâti en briques liées au mortier, se situait au sud du mur de ceinture occidental de l'escalier. Recoupée par plusieurs creusements datant de la destruction du bâtiment, cette structure ne nous est parvenue que sous une forme tres fragmentaire.

Un tuyau d'adduction en plomb d'environ $10 \mathrm{~cm}$ de diamètre se trouvait dans la moitić orientale du dallage à la limite entre celui-ci et le radier de l'escalier ; sa fonction de canalisation ne fait guère de doute.

Enfin, une structure en creux de faibles dimensions, aux parois enduites de mortier hydraulique rose, se trouvait à l'extrémité orientale du dallage. Fn arrière, au nord de ce bassin, se trouvait un " socle " bâti en briques et galets liés au mortier (fig. 13). Il s’agit vaiscmblablement des vestiges d'une fontaine, peut-ĉtre alimentée par le tuyau en plomb.

De tels aménagements (aire dalléc, système d'adduction) sont connus par exemple devant le temple de SaintBertrand-de-Comminges (Sapòne, 1933, p. 12 sq.; (xrenier, 1958, p. 334 ; Badie et al., 1994).

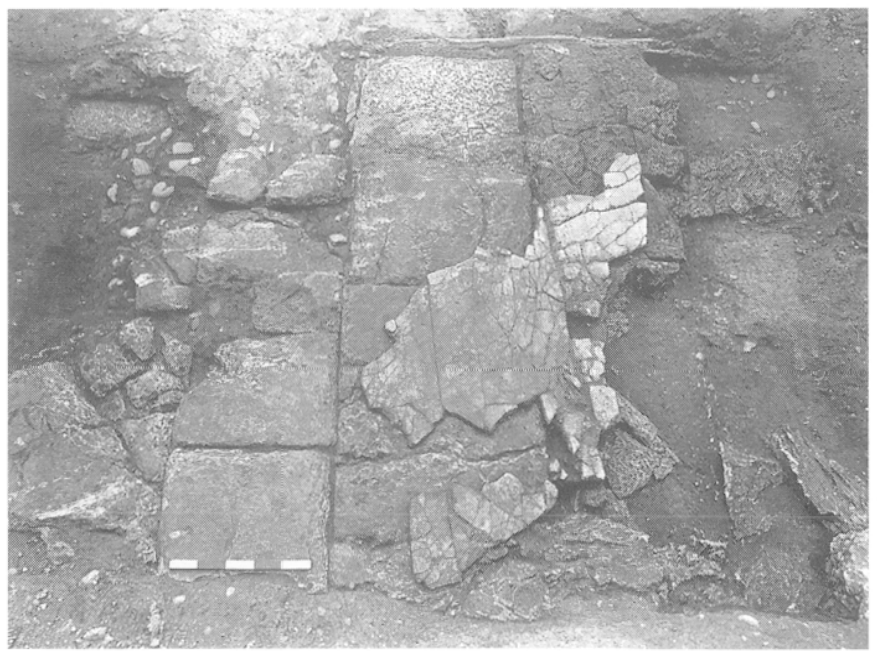

Fig. 12. Vue gémérale du dallage au pied de l'escalier du temple (dalles en calcaire du Haul-kimpire reconovertes par des éléments de placage déposés). Au fond, le petit tuyau en plomb longeant le podium de l'escalier (photo L. (irimbert). 


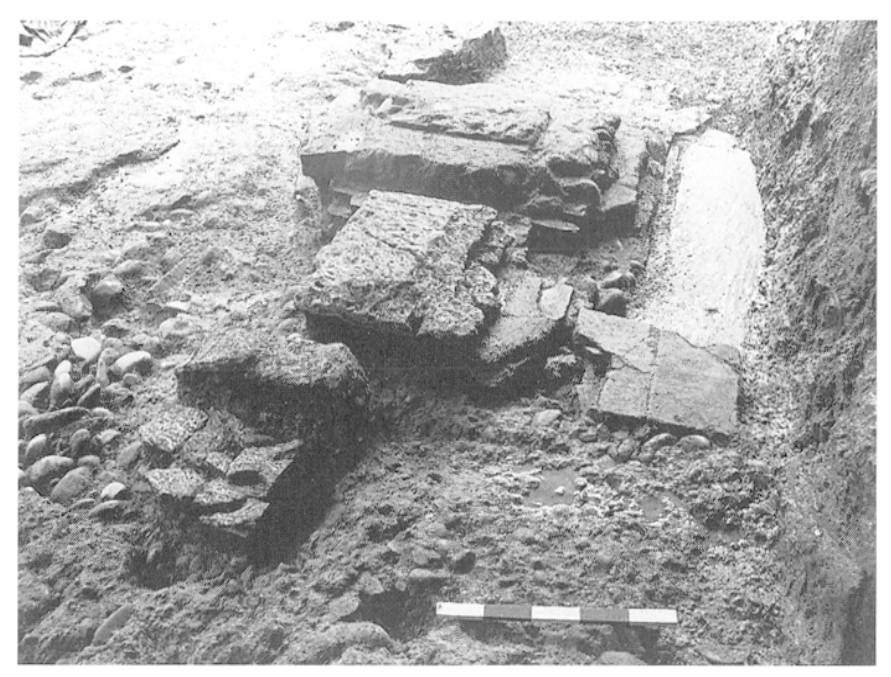

Fig. 13. Fontaine située à l'extrémité est du dallage : socle en magonnerie et bassin en mortier rose (photo L. L.lech).

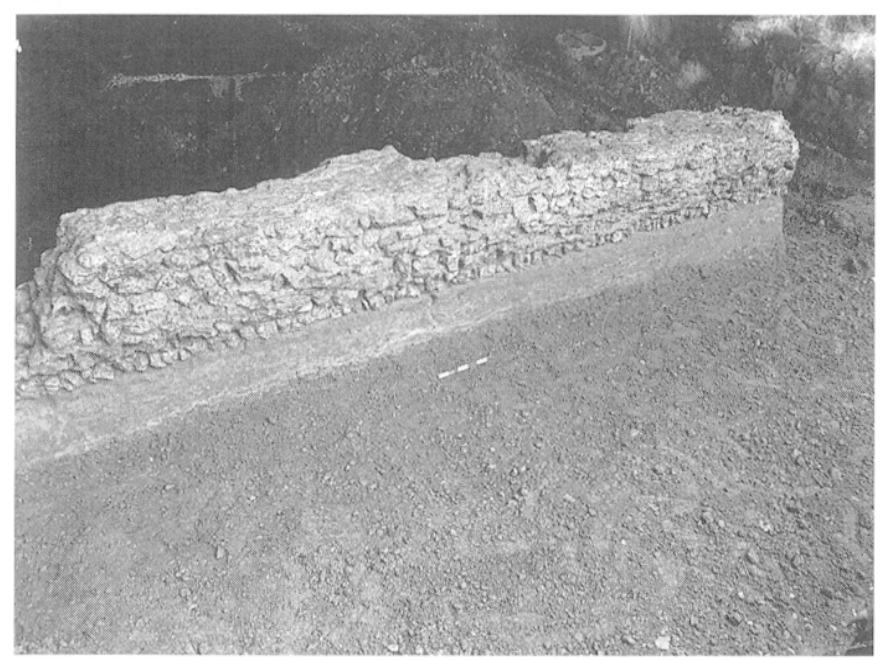

Fig. 14. Vue gémérale du soubassememl du mur est du portique longeant le cardo serondaire (photo $I$. (irimbert).

\section{LE PORTIQUE}

Ia fouille de la zone située à l'est du temple a livré les vestiges d'une structure monumentale identifiable à un portique (fig. 14). D'orientation nord-sud, celui-ci se compose de deux murs distants de $10 \mathrm{~m}$, parallèles au sanctuaire. Ic mur occidental se trouve à $19 \mathrm{~m}$ du temple. Complètement récupéré au Moyen Âge, il ne nous est parvenu qu'en négatif, sous la forme d'une tranchée d'épierrement.

Le mur oriental, d'une largeur de $0,90 \mathrm{~m}$, épargné par les fosses médiévales et la halle métallique du XIX“ s., est beaucoup micux conservé. D'une hauteur de $0,80 \mathrm{~m}$, la semelle de fondation, constituée de blocs calcaires grossièrement équarris et liés au mortier, repose sur un lit de blocs calcaires disposés en épis. Des traces de soubassements de pilastres de $0,9 \mathrm{~m}$ de large pour $0,35 \mathrm{~m}$ de profondeur, espacés tous les $4 \mathrm{~m}$ environ, ont été observés contre le parement oriental de ce mur; ils rythment l'édifice le long du cardo.

L'espace situé entre les deux murs étant profondément bouleversé par des latrines modernes et des fosses médiévales, il ne nous a pas été possible de reconnaître des éléments intermédiaires (supports de colonnade axiale) identiques à ceux retrouvés dans l'aile ouest du portique du temple lors de la fouille de la station de métro Esquirol en 1990 (Collectif, 1995, p. 49-50). Des fragments de tegulae, de même module que celles du temple, retrouvés à l'est du mur oriental peuvent nous donner quelques indications sur la couverture de cet ensemble. Ce portique devait délimiter l'area sacra du temple à l'est, au nord et à l'ouest. Par son plan, il se rapproche des cryptoportiques entourant certains temples à Narbonne (Perret, 1956, p. 7), à Lyon au "Verbe Incarné " (Mandy, 1983, p. 25-26), à Aoste (Manino, 1969) et à Conimbriga (Étienne, 1985, p. 5). Néanmoins, le peu de puissance des substructions du bâtiment de la place Esquirol interdit d'y voir un cryptoportique stricto sensu, c'est-à-dire comportant un étage enterré. Il convient plutôt de le rapprocher de portiques doubles entourant d'autres temples de fora, par exemple Virumum ou Ampurias (Mar, Arbulo, 1985; Milne, 1992, p. 107).

L'élévation de ce portique reste conjecturale. Toutefois, elle devait être identique à celle de laile se situant à l'ouest du temple, aperçue à la fin du XIX"s. (Malafosse, 1893) et fouillée partiellement en 1990 (Filippo, 1993a, p. 69 ; Collectif, 1995, p. 49-50) ; clle possédait une colonnade axiale et un revêtement de petits moellons calcaires (opus vittatum), dont quelques exemplaires ont été remarqués dans la tranchée de récupération du mur occidental è à proximité du mur oriental de notre aile.

Ia décoration de ce portique (cf. D. Cazes, in : Collectif, 1995, p. 53-58) pouvait faire appel à des élé- 
ments de marbres divers, massivement remployés dans une structure méroringienne s'appuyant sur le mur oriental de celui-ci (cf. infra, p. 219).

Les fragments architecturaux les plus nombreux découverts dans le secteur sont des éléments de placage de colonne ou de pilastres rudentés en marbre gris des Pyrénées. Ces derniers sont reliés entre eux par des agrafes scellées au plomb. I.eur diamètre, avoisinant sans doute $1,50 \mathrm{~m}$, témoigne de la présence d'un édifice de très grandes dimensions. I ces fragments de chapiteaux en marbre des Pyrénces retrouvés dans le même contexte stratigraphique que ces placages sont ornés de feuilles d'acanthe et de frises d'oves et de dards; cette décoration peut se rattacher à l'ordre composite. Par leur style et leurs proportions, ces fragments doivent être rapprochés d'un morceau de chapiteau colossal (hauteur conservéc : $0,80 \mathrm{~m}$ ) trouvé dans l'area, remployé dans une structure postmédiévale. Le morceau appartenait sans aucun doute, malgré son piètre état de conservation, à la partie supérieure d'un grand chapiteau corinthien ou composite (fig. 15). Deux observations le prouvent : le lit d'attente supérieur, avec un trou de louve pour le soulèvement du chapiteau, ainsi

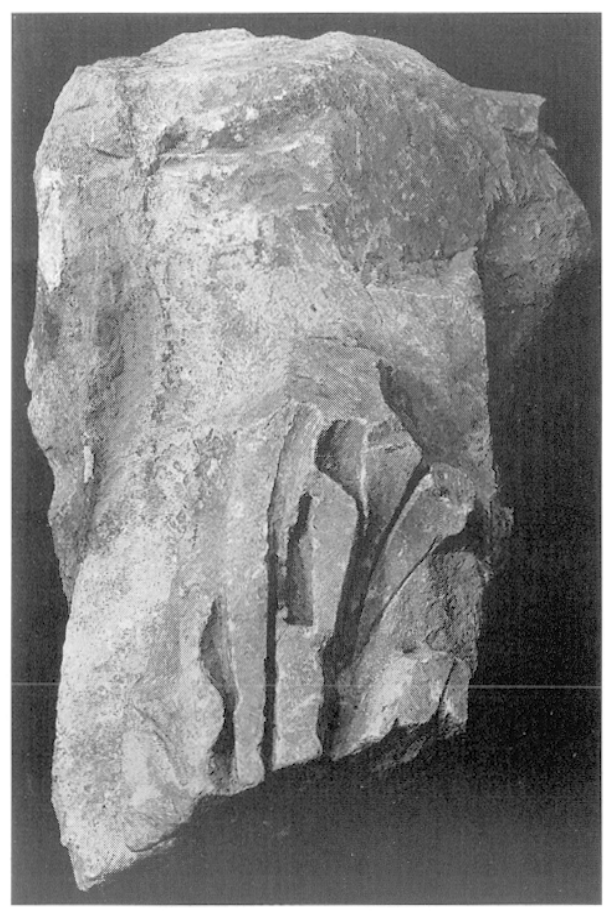

Fig. 15. Cros fragment de chapiteau corinthien ou composite, en marbre des Pyrénées (hauteur : $80 \mathrm{~cm}$ ) (photo musée Saint-Raymond). que la position et le type des feuilles encore préservées sur l'un de ses côtés. Celles-ci sont au nombre de trois : en bas, les vestiges des deux premières indiquent un premier rang qui ornait la première couronne au bas du chapitéau. À l'arrière-plan de celles-ci s'élevait la nervure axiale d'une feuille de la seconde couronne, dont la partic latérale de droite, avec son évidement
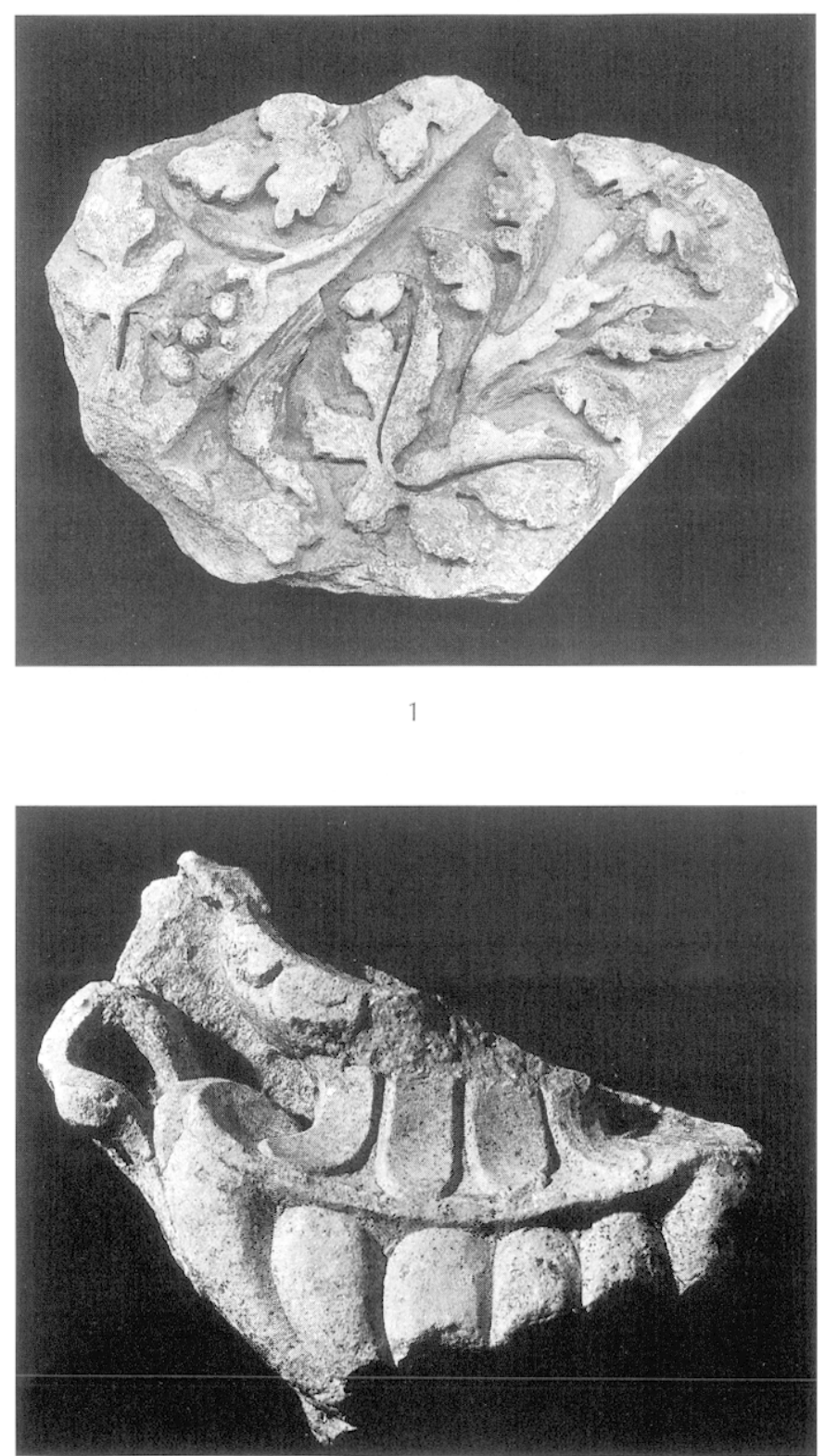

Fig. 16. 1, fragment d'encadrement monumental en marbre des Byrénées ; 2, élément d'encadrement monumental (?), en marbre des Pyrénées, à décor de canthare, provenant du secteur du portique et réutilisé dans une structure du VIr s. (photos musée Saint-Raymond). 




Fig. 17. Coupe stratigraphique cumulative du porlique et du cardo secondaire. En fond de stratigraphie, égout augusto-tiberien domt la vôute a été détruite par un puisard du V's. Les niveraux de voirie se succèdent jusqu'à la fin du V's., malgré la réduction de la bande de roulement suivie de l'installation d'un bâtiment au début du VI's. On remarquera les recharges de la premiere moitie du Ir s. (1424 et 1407) coupées par la fondation du portique du temple (3113) (relevé L. Llech).

caractéristique fait au trépan el quatre digitations, est l'indice majeur pour l'étude et la reconnaissance du chapitcau. C'est à la fois beaucoup - car l'on a ainsi la seule preuve de l'existence de grands chapiteaux monumentaux sur le site d'Esquirol - et très peu pour l'analyse du style de l'ouvre et sa datation. Toutefois, on peut juger de la qualité d'exécution de ce morceau qui témoigne d'un faire rapide. Ie mouvement de la feuille parât néanmoins énergique et, vu à une asse\% grande distance, le chapiteau devait jouer sa fonction dynamique. À titre d'hypothèse et si l'on suit la classification proposéc par
D. Tardy pour les chapiteaux corinthiens de Saintes, l'exuvre pourrait tout à fait appartenir au $\mathrm{I}^{\mathrm{rr}} \mathrm{s}$. (écude 1). (azes).

Cette décoration de marbre était sans doute complétée par des encadrements dont deux fragments importants ont été retrouvés; ils sont ornés d'efflorescences verticales pouvant jaillir d'un canthare (fig. $16, n^{m} 1$ et 2$)$. On peut comparer ces ćléments sculptés aver des cucadrements similaires découverts à Augst, au sanctuaire de Grienmatt, datant du troisième quart du $I^{n}$ s. (Trunk, 1991, p. 127). 


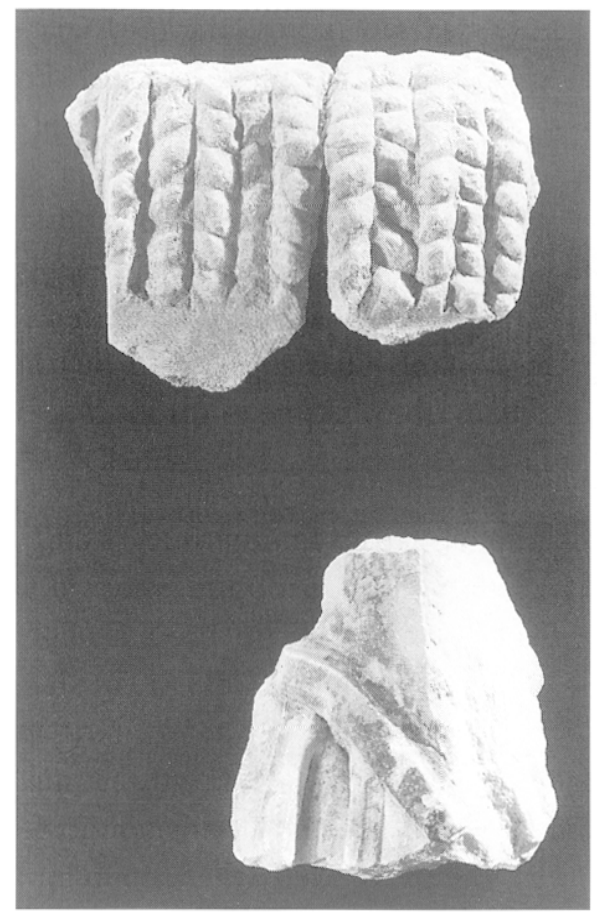

Fig. 18. Fragments de statuaire officielle en marbre (statue cuirassée), jetés dans une fosse du V's. en périphérie du portique (photo muséé Saint-Raymond).

Enfin, un puisard du V*s. percé dans le cardo longeant le portique (fïg. 17), en vue d'atteindre l'égout du I ${ }^{n}$ s., a livré des fragments de statues de marbre brûlés. De nombreux éléments de chutes de draperie, mais aussi deux fragments de statues cuirassées incitent à y voir un décor statuaire à caractère officiel associé au portique, comme c'est souvent le cas en périphéric des sanctuaires majeurs des cités romaines (fig. 18). La mise au rebut de la statuaire des fora à la fin de l'Antiquité, notamment en jetant les statues dans des puits, est un phénomène fréquemment attesté ( $c$. par exemple le portrait de Domitien retrouvé dans un puits près du portique du forum de Munigua mais aussi en Afrique comme à Bulla Regia...).

\section{PHASE D'UTILISATION}

La récupération systématique des matériaux durant l'Antiquité tardive puis l'important décaissement du XIX' s., lors de l'implantation d'un marché couvert métallique arec sous-sol, ont fait disparaître l'essenticl des niveaux contemporains de l'utilisation de l'enscmble monumental. Toutefois, nous avons pu observer à l'ouest du temple une recharge recouvrant par endroits un niveau de galets reposant sur le substrat remanić. Cette recharge, de moins de 10 cm d'épaisseur, est composéc d'éclats de calcaire mêlés à du limon, associés à du mobilier céramique. Neuf niveaux représentatifs comprenant au total 874 tessons ont ćté étudiés. Il s’agit pour la plupart de remblais de construction synchrones, localisés sur la périphérie du temple (fig. 19). Bien que perturbés sur leur partie sommitale par les niveaux de destruction de la fin du IV"s., ils ont permis d'établir une datation assez précise de la fondation du temple, de l'area et du portique.

I a céramique sigillée associée, à $90 \%$ originaire des ateliers de La Graufesenque, représente $9,7 \%$ du mobilier céramique retenu. I e lot mis au jour se siue dans une fourchette chronologique comprise entre 1 (Halt. 16) et 90 de notre ère (Drag. 37). Toutefois la majorité des fragments sont des productions de la période de transition de Ia Graufesenque (60-80) de notre ère). On rencontre, toujours en faible nombre, des restes de plat Drag. 15-17, de bols Drag. 27 lisses et 29b à décors de rinceaux originaires de Montans ainsi qu'une panse de bol Drag. 37 à motifs végétaux empâtés. On note aussi quelques tessons résiduels de gobelet "pré-sigillée " de type Haltern 16, produits entre 1 et 40.

Ia forme de loin la plus représentée $(64,7 \%)$ est l'encrier Hermet 18 (atramentarium). L'observation des tessons de ce type a donné un nombre moyen équivalant à une dizaine d'encriers, dont deux excmplaires exceptionnels à vernis "marbré " (étude A. Vernhet). Ia majeure partic des fragments présente encore des traces d'encre noire sur leur partie interne. La découverte de ce type d'objet en proportion importante, alors qu'il est généralement très rare, laisse entrevoir des activités spéciliques liées au temple d'Esquirol (écoles?, archives?), (fig. 20). Un exemplairc identique d'atramentarium a ćté découvert dans un contexte flavien près du temple de Saint-Bertrand-de-Comminges (Badie et al., 1994, p. 58).

Ia céramique commune à postcuisson oxydante constitue le lot le plus important de la zone étudiéc $(36,4 \%)$ (étude I. Ilech). Les formes identiliables sont essenticllement des urnes à lèvre épaissie de petites dimensions. Les récipients ouverts sont représentés par des coupes ou des jattes à pied annulaire. On remarque 


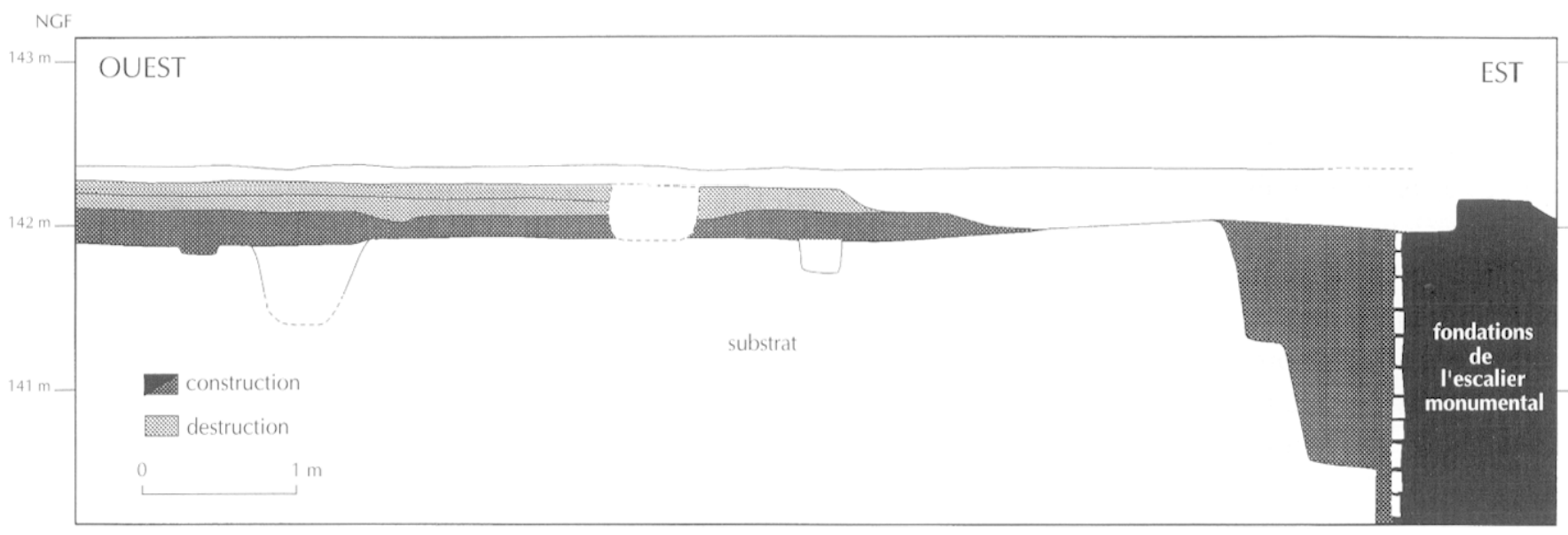

Fig. 19. Coupe est-ouest à l'ouest du podium du temple montrant les nizéaux de comstruction et de destruction de celui-ci (relequé L. (irimbert).
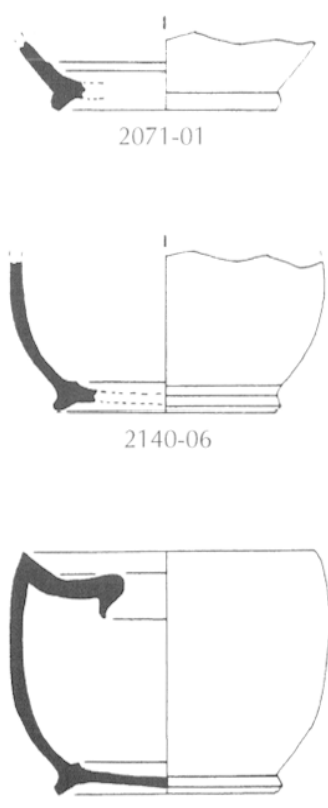

2013-2140-2071

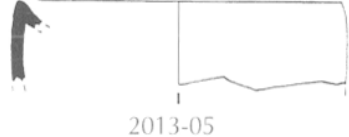

2013-05

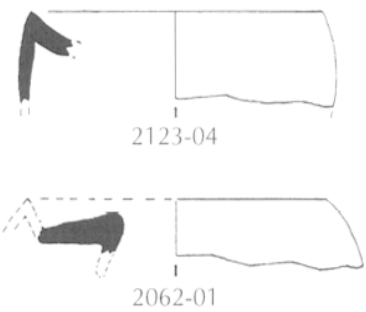

Fig. 20. Encriers Hermet 18 trouvess sur larea, appartenamt is la phase de construction de l'ensemble momumental (dessin C. ('habut).

aussi quelques éléments appartenant à des cruches à manchon ou à des pichets proches des formes produites dans l'atclier de Sallèles-d'Aude. Toutefois, la qualité de leur pâte est sensiblement différente : de couleur rouge orangé, elle présente une forte proportion de dégraissant donnant un aspect grossier à l'ensemble de ces récipients. Même si la mauvaise conservation de cette céramique a nui à son identification typologique, les formes présentes offrent des caractères classiques pour la région

si l'on se réfère aux collections issues d'autres sites datant de la même période.

I a céramique commune à postcuisson réductrice présente des caractères généraux assez semblables à ceux des productions découvertes en milieu augusto-tibérien, ce qui n'est pas étomnant en soi en raison de leur filiation directe. En revanche, on constate une certaine évolution typologique avec la disparition des urnes à cuire à panse peignée au profit de nouvelles formes : les cruches ou cruchons paraissent constituer dans cette période le type le plus utilisé. I es formes ouvertes, quant à elles, sont peu représentées : on ne compte que quelques fragments de bords pouvant appartenir à des jattes ou à des coupes assez frustes.

On note également un pourcentage encore signilicatif de céramiques à pâte claire dites « italiques » $(13,4 \%)$. I ces formes appartiennent exclusivement à des opnochoés à pâte légèrement micacée munies d'une anse bifide, trifide ou exceptionnellement torsadée. I a proportion encore importante de ces récipients pourrait indiquer une durée de production de ces formes jusqu’à la fin du I" s. Il se peut néanmoins que nous soyons en présence d'imitations locales.

L'apparition de la céramique doréc all mica blanc, appelée communément "micacée ", marque aussi cette séquence chronologique. Rencontrée en faible quantité sur le site $(1,6 \%)$, elle offre un registre de formes asse standardisées typiques de la région toulousaine. Il s'agit presque exclusivement de formes ouvertes représentées 
par de petites coupes carénées, alors que quelques tessons appartiennent à de petites urnes à bord déjeté ainsi qu’à des gobelets ovoïdes.

I.es fragments d'amphores $(24,80 \%$ du mobilier (éramique) offrent un eventail typologique relativement varić. I a majeure partie des tessons provient de la péninsulc Ibérique : on rencontre en grandes proportions des fragments de type Dressel 20 et plus sporadiquement des éléments d'amphore à saumure Pascual 1. I.es récipients d'origine italique sont exclusivement du type Dressel 2-4. I.es amphores gauloises, retrouvées en faible nombre, sont représentées par les formes $4 \mathrm{ct}$ 5. Enfin, on note un petit nombre de tessons de Crétoise 4-Dressel 43 reconnaissables à leur anse munie d'un ergot caractéristique.

Ce lot donne une fourchette chronologique large, comprise entre la première moitié du I" et le début du II' s.; elle ne contredit toutefois pas les datations fournies par la céramique sigillée.

I e mobilier antique issu de la zone monumentale permet donc de proposer une date de construction du temple et du portique entre 60 et 100 de notre ère (céramique sigillée, fragments de lampes à volutes de type Dencauve 4, cf. étude L. Llech et A. Vernhet).

D'un point de vue stratigraphique, ces horizons peuvent être contemporains de la construction du sanctuaire puisqu'ils sont mêlés à des éclats de calcaire semblant correspondre à un niveau de travail postérieur au creusement des fondations. Un horizon semblable a été découvert autour du temple de Saint-Bertrand-deComminges (Badic et al., 1994, p. 46 et 61). Place Esquirol, ces remblais devaient être recouverts par un niveau de circulation peut-être matérialisé par des dalles identiques à celles recueillies au sud du temple, mais ayant dî faire l'objet d'une récupération systématique vers l'an 400 .

Concernant le temple, aucun mobilier à caractère " cultuel " n'a été mis au jour. Néanmoins, à l'angle sudest du podium a été découverte, dans un contexte stratigraphique incertain, une vidange de foyer perturbée par unc fosse de l'Antiquité tardive. Elle a livré un lot homogène de 115 osscments animaux dont environ un tiers est plus ou moins carbonisé en fonction de sa position par rapport aux flammes. L'essentiel de cet ensemble, étudié par I. Rodet-Belarbi, est constitué par les restes d'un bouf ou d'un taureau (Bos taurus) de forte corpulence dont le crâne porte la trace d'un coup ayant tranché les frontaux transversalement. I a largeur de l'instrument utilisé était de 25 à $30 \mathrm{~cm}$ au minimum. S'il ne peut guère s'agir d'un coup de couperet destiné à fractionner la boîte crânienne afin d'en extraire la cervelle - cette dernière aurait été gravement endommagée par la brutalité du coup -, il ne peut s'agir non plus du coup de hache asséné à l'animal afin de le tuer car il doit être porté sur la nuque, scène longuement illustrée sur divers bas-reliefs (Prieur, $1982 ; 1988$, p. 178), à moins que la bête n'ait relevé la tête au dernier moment. Ce fragment de crâne avec une telle découpe est unique sur le site du parking Esquirol.

\section{PHASE DE DESTRUCTION}

\section{LE TEMPLE ET L'AREA}

À l'est et surtout à l'ouest du podium et de l'escalier monumental a ćté mis en évidence un niveau composé d'éclats de calcaire parmi lesquels de très nombreuses nervures de colonnes débitées des tambours. Cette couche recouvre directement le niveau à encriers précédemment cité. Il est probable que cet horizon de 20 à $30 \mathrm{~cm}$ d'épaisseur témoigne de la mise à bas de la colonnade du proncos suivie d'une opération de retaillage in situ de ses composantes. I ces tailleurs de pierres ont alors abandonné sur place les déchets résultant de cette récupération des matériaux, c'est-à-dire tous les éléments en relief (arêtes, moulures de bases, sculptures...). Dans le même horizon sont présents de nombreux fragments de plaques de marbre gris, appartenant sans doute à un revêtement externe, indice supplémentaire d'un démontage systématique des superstructures du temple (fig. 21, $\left.\mathrm{n}^{\circ} 1\right)$.

Cette destruction du sanctuaire a lieu entre la fin du IV et le début du Vv s., datation effectuéc d'après le mobilier abondant issu des nombreux remblais de démolition (imitations d'antoniniens du III' s., monnaies de Constantin I et II, Crispus et Constance II au type GIORIA EXERCITSS, types frustes de la seconde moitié du IV's., céramique à engobe argileux, dérivée de sigillée paléochrétienne languedocienne grise et orangée, lampes de type Atlante VIII, amphores hispaniques et africaines...).

Après cette destruction systématique qui revêt sans doute un caractère officiel ( $c$. infra, p. 232), on assiste 
à un réaménagement de l'espace autour du temple dans le courant du $V^{*}$ s. (dérivée de sigillée paléochrétienne languedocienne à dominante grise, dérivée de sigillée paléochrétienne atlantique, lampes de type Atlante X, amphores proche-orientales... I.cs types monétaires restent similaires, avec cependant une plus grande fréquence d'imitations légendées ri:I. Thill

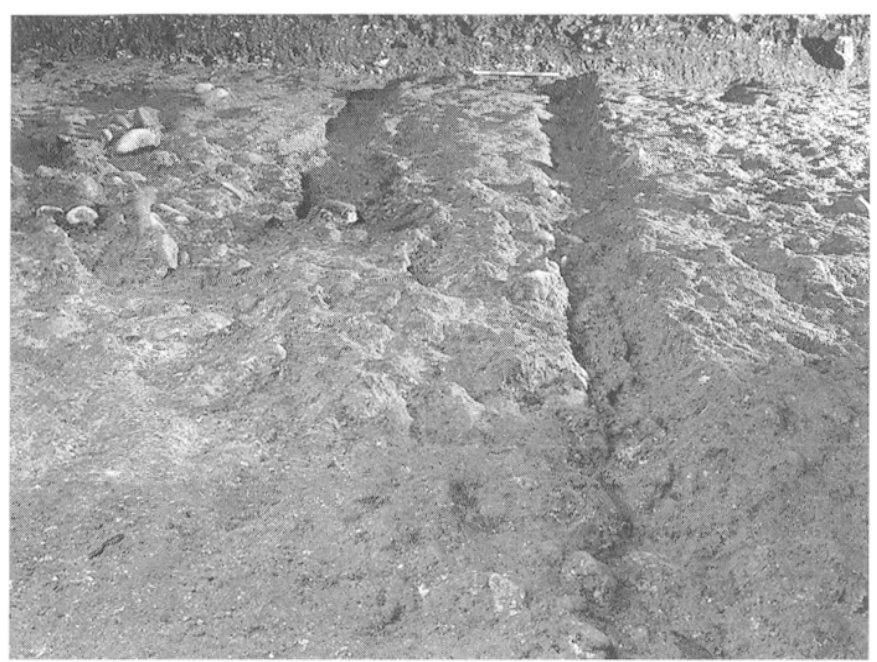

1



Fig. 21. 1, vne du niveau marquand la destruction des superstructures du temple, comportant des ormieres (conglomérat de délmis calcaires) (photo L. (irimbert) ; 2, nizerau de circulation du Vrs., a l'ouest du podium, compossi de matériaux de destruction provenant du temple : blocs calcaires, briques, Iniles et galets (photo I. Llech).
RLPPARAT()). À l'ouest du podium, un important niveau de circulation est mis en place. Les recharges successives sont composées de matériaux de démolition concassés et damés (éclats de marbre et de calcaire, teguke de grand module) issus en grande partic du temple (fig. 21, $\mathrm{n}^{\circ}$ 2). Au sud du podium, dans l'axe de l'escalier, le revêtement de l'area est partiellement arraché et remblayé, puis recouvert d'un nouveau "dallage". Il se compose de plaques de marbre sans doute issues de la démolition du temple, retournées et déposées en respectant quasiment l'ordonnance de l'ancien dallage. Un foyer provisoire est installé sur le radier de celui-ci, fortement endommagé par endroits par des récupérateurs de matériaux ". À l'est du podium, des niveaux semblables ont dû être installés, mais ils ont souffert d'aménagements médiévaux.

Lne dernière phase, probablement de la fin du V*ou du VI* s. d'après la stratigraphie el l'étude du rare mobilier, voit l'installation de structures en matériaux légers au sud-ouest du podium, dont les poteaux perforent le niveau de circulation tardif (fig. 22). À l'est, un mur bâti arec des fragments de sols antiques, perpendiculaire à la paroi orientale du temple, s'appuic contre ce dernier. En périphérie du podium et de l'escalier, plusieurs fossesdépotoirs remplies de matériaux de destruction sont mises en place. Échelomnées chronologiquement entre le début du V* et le début du VI" s., elles respectent le parement du podium, à l'exception d'une fosse qui semble avoir perforé les substructions du pronaos; cette dernière est datable par le mobilier céramique des VIVII" s. (ollae à bord en bandeau).

Il semble donc qu'au VT's. le podium subsiste en ćlévation, malgré la ruine des superstructures.

\footnotetext{
2. Il laut signaler dans ce contexte la présence inattendue d'un crâne humain, isolé dans un remblai de démolition du $V^{w}$ s. au pied de l'escalice monumental. Il s'agit d'une calvaria d'adulte mâle. Située au contact du radier de l'arén. légèrement décalée vers l'ouest par rappont a l'axe de l'escalier, elle reposait sur l'occipilal. Il ne peut s'agir d'une inhumation stricto sensu: cest par ailleurs le seul ossement humain décourert en contexte sur le site. Sa presence, à lendroit précis ou

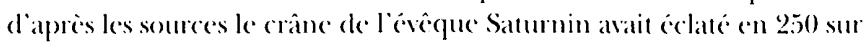
les marches du (appitolium ( 9 infira, p. 223). pourrait ête intentionnelke, à une époque où le culte de l'évêque, a travers celui de se's reliques, est en plein essor. Il serait bien sûr aventureux daller plus loin dans l'analyse.
} 


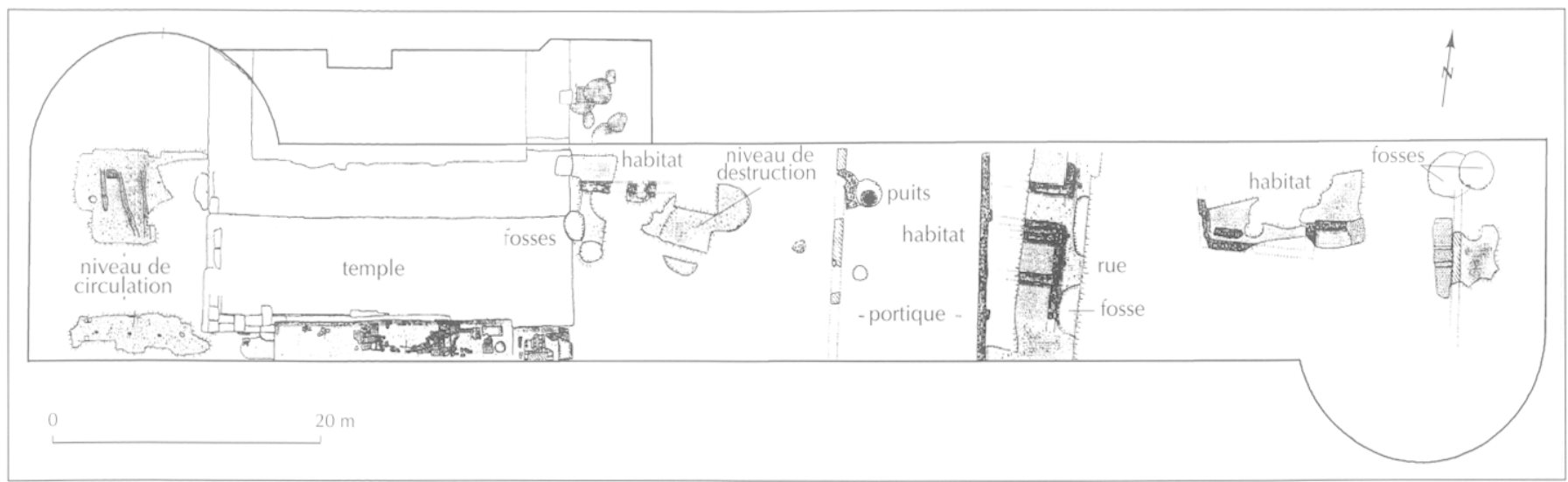

Fig. 22. Structures du V-VT s. : habilats, fosses el niveaux de circulation (releré L. L Lech).

\section{LE PORTIQUE}

Le secteur du portique ayant été fortement perturbé par l'urbanisme moderne et le marché métallique, il a été difficile d'appréhender les différentes phases de sa destruction. I ce mur occidental (côté area) a fait l'objet d'un épierrement intégral entre 1100 et 1300 d'après le mobilier céramique présent dans la tranchéc de récupération. I.e mur externe longeant le cardo a sans doute été conservé longtemps en élévation, même si son revêtement paraît avoir ćté prélevé et débité au VI*s. pour ćtablir les fondations de murs à solin (marbres, tuiles, calcaire et surtout galets liés à la terre) constituant un bâtiment à petites pièces, parallèle au portique et adossé à lui, empiétant sur la chaussée de l'ancien cardo provisoirement abandonné. Ainsi le portique comme le podium influencent-ils encore l'urbanisme mérovingien.

Des structures parasites comparables autour du temple du forum de Saint-Bertrand-de-Comminges ont récemment été mises en évidence (Badie et al., 1994, p. 67).

\section{INTERPRÉTATION DES DONNÉES}

I.es résultats de la campagne de fouilles de 1992-1993, complétés par un dépouillement systématique des sources et de la bibliographie, permettent de proposer une identification ainsi qu'une hypothèse de restitution du temple.

\section{IDENTIFICATION DU SANCTUAIRE : LE CAPITOLIUM DE TOLOSA?}

Un faisceau d'indices archéologiques, topographiques et textuels converge pour identifier le temple au sanctuaire de la triade capitoline, dont la présence autour de la place Esquirol était, rappelons-le, soupçonnéc par l'historiographie moderne (Martin-Chabot, 1918; Labrousse, 1968).

\section{DONNÉES TOPOGRAPHIQUES : LE TEMPLE PRINCIPAL DU FORUM DE TOULOUSE}

L'importance du sanctuaire de la place Esquirol réside, outre ses dimensions monumentales, dans la place qu'il occupe au sein de la cité antique, au coeur de celle-ci. Son portique est longé à l'ouest par le cardo maximus ( $f$. infra, p. 229) ; au sud, l'area est vraisemblablement bordée par le decumanus maximus. Il se situe donc au nord-est du croisement des deux artères principales de la ville antique. Mieux, l'étude du cadastre médiéval, conjuguée aux découvertes anciennes et aux fouilles récentes, permet de penser qu'il s'agit du temple du forum, occupant le côté nord de celui-ci (cf. infra, p. 230, fig. 28).

Cette fonction de sanctuaire principal du forum restreint le nombre des dédicaces envisageables. Il pourrait s'agir d'un temple du culte impérial, celui-ci ayant été particulièrement développé en Narbonnaise (Gros, 1991, p. 40-41). En effet, les études récentes sur le culte impérial et ses sanctuaires urbains ont montré l'importance du 
phénomène depuis Auguste et durant toute l'Antiquité classique. Ainsi, de nombreux temples principaux de fora relèvent certainement du culte impérial ( $c f$. par exemple Étienne, 1985; Hanlein-Schäfer, 1985; Collectif, 1990; Trunk, 1991 ; Balty, 1993; (Gros, 1996). Plusicurs chercheurs ont d'ailleurs insisté sur l'" impérialisme" de la dévotion rendue aux empereurs, entraînant un affaiblissement des cultes traditionnels issus de la République et en particulier celui de la triade capitoline ( $c$. par exemple Éticnne, 1985, p. 15; (Gros, 1986). Ainsi, les temples du culte impérial en Narbonnaise auraient en quelque sorte imité le Capitolium des colonies italiques (Gros, 1990a, p. 57) en prenant leur place dans la partie nord du forum. Ces temples du culte impérial sont quasi systématiquement entourés de porticus triplex, portiques ou cryptoportiques formant un véritable " écrin " autour du temple (Étienne, 1985, p. 12 ; Balty, 1993). Ceci, joint à un hypercriticisme systématique dont ont fait l'objet les sources de l'Antiquité tardive et du Haut Moyen Âge se référant aux Capitolia, a conduit depuis L. Bianchi (1973, p. 75) à minimiser le rôle présumé des temples consacrés à la triade capitoline sous l'Empire, notamment en Gaule. Cependant, des recherches récentes ont montré que le culte capitolin n’a pas été détruit par le culte impérial (Todd, 1985, p. 62). Ainsi la plupart des Capitoles républicains continuent à fonctionner sous l'Empirc (comme à Ampurias par exemple), alors que d'autres sont restaurés ou nouvellement créés un peu partout dans les provinces, jusqu'au III's. De même, la présence d'un portique " en pi " entourant le sanctuaire principal d'un forum ne saurait préjuger du culte qui y est rendu, impérial ou capitolin (Fishwick, 1992).

Il en résulte une extrême difficulté à identifier le culte rendu dans les sanctuaires majeurs des fora de Gaule et des provinces voisines. Cette hésitation des archéologues et des historiens devant la nature exacte du principal lieu de culte civique est patente, notamment en Espagne (Blutstein-L atremolière, 1991, voir cataloguc des " places capitolines"). Ici comme ailleurs, seule une minorité de sanctuaires peut être attribuéc de façon sûre au culte impérial ou à celui de la triade capitoline, la majorité restant "anonyme ". Ce constat peut aussi s'appliquer à la Gaule où, si peu de Capitoles ont été découverts jusqu'à présent (Todd, 1985, p. 64), le culte de la triade capitoline est attesté et plusieurs sites potenticls existent (Martin, 1991, p. 158 sq.).
Pour en revenir au temple de Toulouse, l'espace compris entre la place Esquirol et la place Rouaix constitue le point culminant de la cité antique à $143 \mathrm{~m}$, dominant de $13 \mathrm{~m}$ le lit de la Garonne (Iabrousse, 1968, p. 41 ; Baccrabère, 1977 , p. 67-68); il est tentant, avec les réserves d'usage, de mettre ceci en relation avec la prescription de Vitruve $(I, 7,1)$ : « Les temples des dicux tutélaires, de même que ceux de Jupiter, Junon et Minerve, seront placés à l'endroit le plus élevé afin que, de là, on découvre la plus grande partie des murailles de la ville."

Par ailleurs de nombreux Capitoles ont été construits sur le forum, surtout à son extrémité nord, côté considéré comme le plus noble et lieu privilégié du culte municipal (Bianchi, 1949, p. 365-368). L'exemple de Virunum montre à ce sujet une organisation de l'espace très proche de celle de Toulouse (Vetters, 1977, p. 315). Il arrive que les deux traditions se rejoignent, l'extrémité septentrionale du forum étant aussi un lieu élevé, comme c'est le cas à Florence et Brescia (Bianchi, 1949, p. 369) où l'escalier débouche vers le sud face au forum. Ie site et l'orientation du temple de la place Esquirol pourraient avoir été choisis en fonction de cette double tradition.

Ia forme générale du podium du temple peut, clle aussi, renvoyer à un Capitole : le rapport longucur/largeur pourrait être (cf. infra, p. 221) de $4 / 3$ à Toulouse $(120 \times 90$ pieds de $29,6 \mathrm{~cm})$, proche du rapport de $6 / 5$ que préconise Vitruve pour les temples toscans-étrusques à trois cellae (IV, 7, 1, cf. Gros, 1990b). Ce plan semble être à l'origine des Capitoles républicains et impériaux précoces (Cagiano de Azevedo, 1940, p. 73; Bianchi, 1949, p. 373 ; Castagnoli, 1959, p. 326). Des rapports comparables existent au Capitole de Rome, de Narbonne, Cirta, Timgad (Barton, 1982, p. 334), Xanten (Hin\%, 1975), Cologne (Hellenkemper, 1975, p. 804-806), Virunum (Castagnoli, 1959, p. 329). On notera les dimensions très proches des trois podia au regard du temple de Toulouse : $28 \times 34 \mathrm{~m}$ à Cologne, $33,9 \times 26,9 \mathrm{~m}$ à Cirta, $24,6 \times 34,9 \mathrm{~m}$ à Virunum. Le temple de Toulouse s'insère donc parfaitcment dans une typologie du plan au sol des podit des Capitoles d'Italic, de Germanie, d'Afrique et de Gaule (fig. 23 à 25). En outre, ces temples respectent la prescription de Vitruve (IV, 7,1$)$ qui stipule " que la longueur soit divisée par moitié, la partie située à l'intéricur étant assignée à l'espace des salles cultuelles et la partic la plus proche de la façade étant réservée à l'ordonnance des colonnes " (texte établi et traduit par P. Gros, 1990b). 


\section{DONNÉES TEXTUELLES}

I.e Capitolium de Toulouse est le scul temple de la ville à ĉtre mentionné nommément par les sources antiques, relayées par les textes du Haut Moyen Âge. I.e souvenir de sa localisation a perduré jusqu'au XIII's. ${ }^{3}$. Tous ces textes sont remarquables par leur homogénéité et leur caractère convergent. Parmi ceux-ci, trois datent de l'Antiquité tardive et cinq sont d'époque mérovingienne. Nous présentons ici les plus significatifs (pour une étude détaillée du corpus of. Boudartchouk, Arramond, 1993).

- Ia Passio Sancti Saturnini (réf. Bibl. Hag. Lat. n 7496, édition Ruinart 1689 ; traduction Baudot et Chaussin, 1935, t. XI, p. 974 sq.) raconte l'histoire du martyre de Saturnin, premier évêque de Toulouse, lors de la persécution de Dèce en 250.

Alors qu'il passe devant le Capitole, situé entre sa maison et son église, Saturnin, jugé responsable du mutisme des statues, est traîné sur les marches du temple où on le convie à sacrifier aux dieux. Devant son refus, il est attaché au taureau préparé pour un sacrifice solennel. La bête, chassée des degrés de l'escalier du temple, entraîne Saturnin dont la tête se brise sur les marches. Son corps sans vie est traîné par le taurcau furieux jusque hors des murs de la ville ( $c$. op. cit.). Ce texte a été rédigé par un clerc toulousain vers $410-420$, sans doute en se servant d'un manuscrit plus ancien ${ }^{4}$.

3. La validité des données textuelles de la fin de l'Antiquité et du début du Moyen Âge se rapportant aux (apitoles a été fréquemment mise en cause ( $c f$. Gros, 1986, p. 112 par excmple), en arguant de l'imprécision du vocabulaire comme de la méconnaissance présuméc de la nature précise d'un Capitolium par les auteurs latins tardifs. Il est néanmoins capital d'étudier ces témoignages sans a priori et au cas par cas, certaines sources pouvant difficilement être mises en doute lorsqu'elles sont convergentes entre elles et corroborées par d'autres témoignages. I.e cas de Narbonne est à cet égard particulic̀rement intéressant puisque le corpus des textes de l'Antiquité tardive et du Moyen Âge se référant au Capitole de cette cité est tout à fait comparable à celui de Toulouse ( $c f$. en dernière analyse le remarquable article de D. Fishwick, 1992, p. 381-420). Un recensement des mentions tardives des Capitolia est en cours par les auteurs.

4. "Cumque supradicto Eipiscopo ad ecclesiam id temporis parvulam juxta Capitolium, quod inter domum suam et domum Dei eral, frequens itus esset ac reditus [...]. Hujus etiam fidei esse episcopum Scaturninum cujus crebo juxta Capitolium transitu ad conspectum viri illus exterrita deorum suorum ora siluissent $[\ldots] .(\$ 2$ et 3$)$.

Omnis sanctum virum insanientum turba circumdat, ac praesinglero uno as duobus diaconibus qui obsequiis ejus adhaeserant, per fugam lapsis, ad Capitolium solus attrahitur [...]. (\$4).
On peut retenir de ce texte l'existence intra-muros, près d'une voie de communication, d'un temple doté d'un escalier monumental et donc d'un haut podium.

I a plus ancienne missa à Saturnin, sans doute composée durant la seconde moitié du Vis. (Fórotin, 1912, p. 31), évoque également en des termes comparables la topographie du Capitolium ${ }^{5}$.

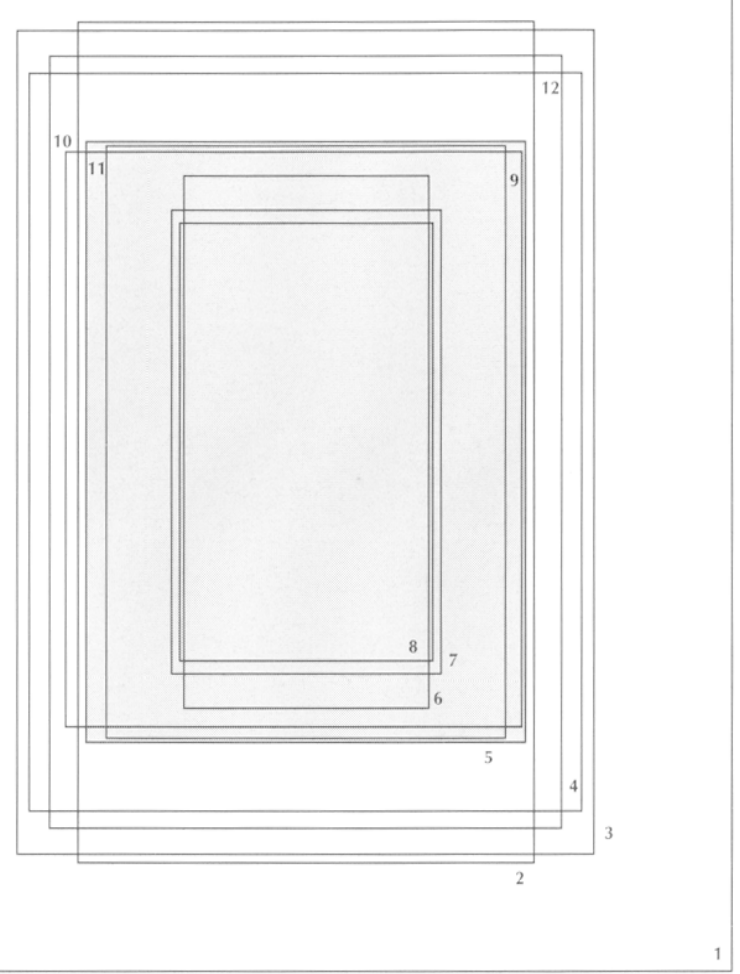

Fig. 23. Dimensions comparées de différents podia de Capitoles (d'après Barton, 1982, complété) : 1, Rome; 2, Cumes; 3, Narbonne; 4, Cirta (grand temple) ; 5, Timgad ; 6, Pompéi ; 7, Ostie (temple d'Hadrien) ; 8 , Thuburbo Maius ; 9, Cologne; 10, Cirta (petil lemple) ; 11, Virunum ; 12, Xanten ; tramé, Toulouse (dessin J.-I. Boudartchouk).

Ad posteriora tauri ipsius defluebat, sancti viri pedes inligant, actumque stimulis acrioribus taurum de superion capitolii parle in plana praecipitant. Nec mora : inter primos descensus ipsius gradus, capite colliso cerebroque excusso ot omni membromum parte corpore laceralo, dignam deo animam christus excepit [...]. " (\$ כ)

5. "Qui quum correplus ad Capitolium duceretur [...] per gradus quibus Capitolium descendebalur demens turba precipital. Statimque inter ipsos primi ordinis gradus confractis capitis compagibus, soluta cerebri interna dissiliunt. " 


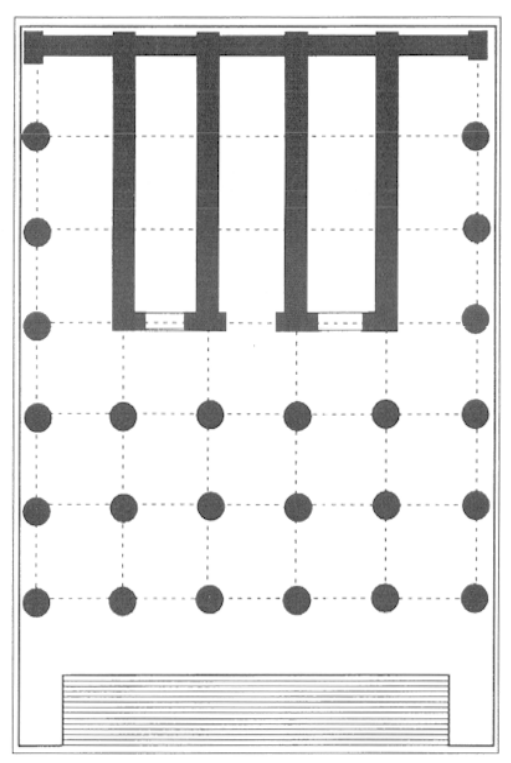

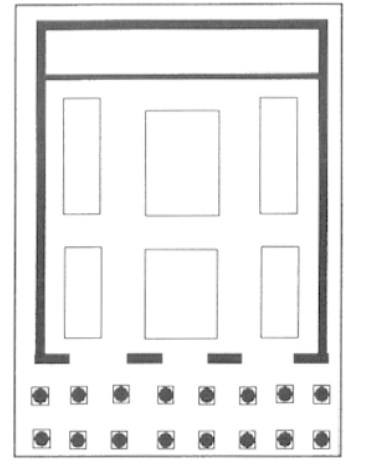

NARBONNE

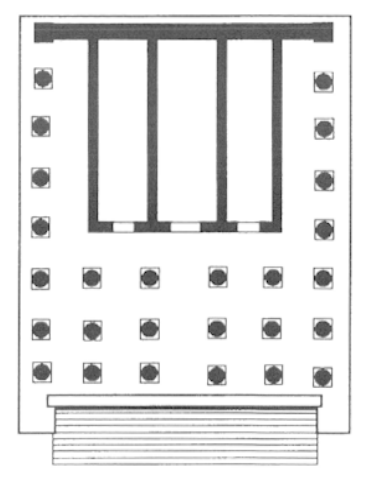

VÉRONE

ROME

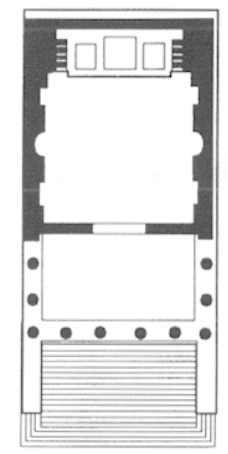

OSTIE

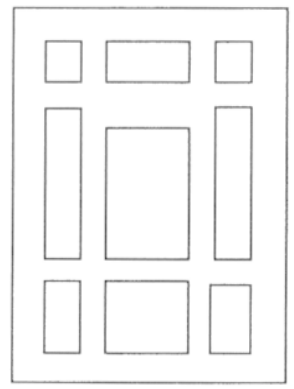

XANTEN

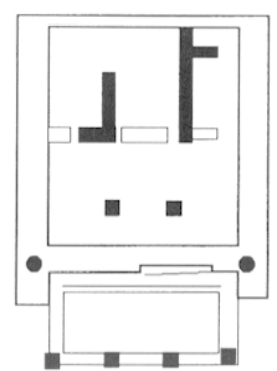

FIORENCE
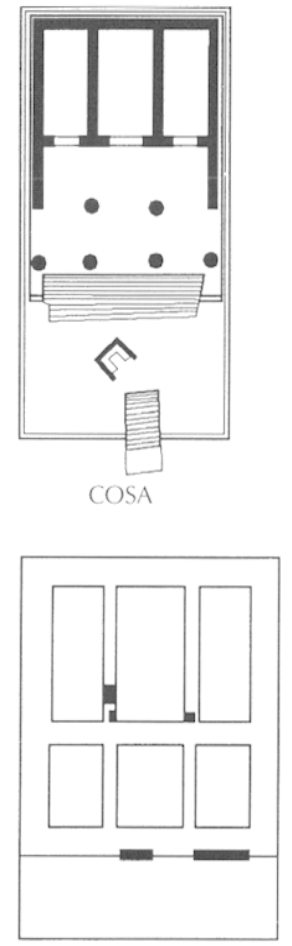

COLOGNE

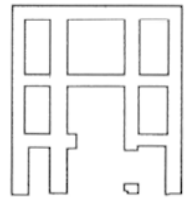

MINTURNA

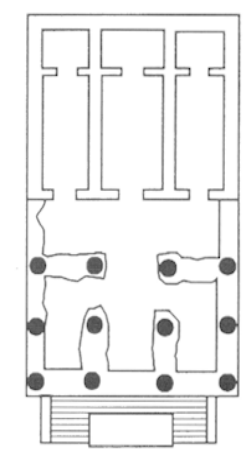

SEGNI

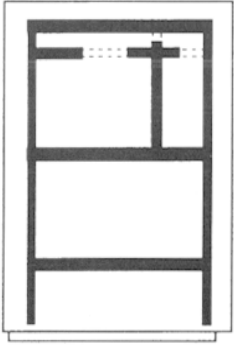

VIRUNUM

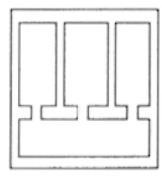

TERRACINA
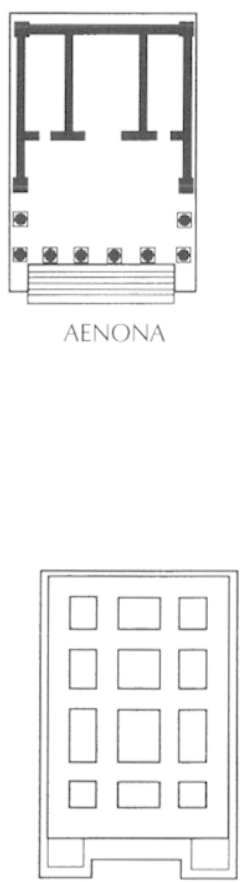

LUNI

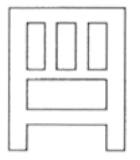

SAGUNTUM

Fig. 24. Plans de (ápitoles d'après divers auteurs (dessin J.-L. Boudartchouk, L. Llech et L. Grimbert). 
- Sidoine Apollinaire, qui a séjourné à la cour wisigothique de Toulouse, dans sa Lettre à Fïrminus (Epist. IX16) écrite vers 481-482, mentionne le Capitole de Toulouse et ses divinités, l'insistance sur Mincrve aux côtés de Jupiter se comprenant d'autant mieux dans le cadre d'une cité qualifiée de Palladia Tolosa. Ceci rend peu probable l'hypothèse du terme "capitole " utilisé au sens générique de " temple paien ", comme l'ont fait rarement certains auteurs de l'Antiquité tardive, relevée par Du Cange ${ }^{6}$.

On peut lire en effet dans le texte de Sidoine : "Celui qui occupa le siège épiscopal de Toulouse et fut précipité du haut des marches du Capitole. Reniant Jupiter et Minerve [...] il fut attaché par la foule égarée au flanc d'un taureau qui n'avait pas connu le joug, afin que la bête, lancée violemment sur les degrés de l'escalier, dispersât dans sa course les membres déchirés du cadavre et teigne les pierres de la pulpe chaude du cerveau [...] ${ }^{7}$.

I. souvenir du temple de la triade capitoline de Toulouse est toujours présent à la fin du VI's. chez Grégoire de Tours et Venance Fortunat.

- Grégoire de Tours se borne à paraphraser la passion du V's. ou un texte proche, qu'il évoque dans son De gloria martyrum (Pat. Lat. I.XXI, col. 749-750) où il mentionne la mort de Saturnin " per gradus Capitolii praecipitatus " ainsi que dans Historia Francorum (éd. Picard, 1886, I, 30) «Ad capitolium duceretur [...] de capitolio praecipitatus".

- Venance Fortunat a composé en 567 deux poèmes en l'honneur de Saturnin alors qu'il était de passage à Toulouse, se dirigeant ou revenant de Galice (Reydellet,

6. Glossarium mediae et infimae Latinitatis, Paris 1883-1887, art. Capitolium. Ces exemples ont été repris et développés notamment dans le Dictionnaire d'archéologie chrétienne et de liturgie, Paris 1907-1965, art. Capitolium. (f. aussi A. Blaise, Dictionnaire latin français des auteurs chrétiens, éd. Brepols, 1954, p. 130. Il est capital d'étudier le contexte précis de ces mentions tardives.

7. Equibus primum mihi psallat hymnus

qui Tolosatem tenuit cathedram,

de gradu summo Capitoliorum

praccipitatum;

Quem negatorem Iouis ac Minervae.

et crucis Christi bona confitentem

vinxit ad tauri latus iniugati

plebs furitunda,

Ut per abruptum bove concitato

spargeret cursus lacerum cadaver

cautibus tintis calida soluti pulte cerelri.

1994, p. XIV). Ces deux poèmes sont liés à la consécration d'une nouvelle église en l'honneur de l'évêque Saturnin, bâtie à l'initiative du duc franc Launebode et de sa femme Berethrude. Le premicr poème (Fortunat, Carm. II-7, of. Reydellet, 1994, p. 59), prononcé sans doute sur le site même lors de la consécration de l'église, est un panégyrique de l'évêque s'inspirant de la passio ou d'un texte comparable. Après avoir rappelé le souvenir du locus du martyre, c'est-à-dire le Capitole ( " ad capitolia duxit "), l'auteur insiste sur le parcours sinucux du taureau dans les rues de la ville. Le second poème (ibid., II8, p. 61-62) a sans doute été prononcé lors du banquet qui suivit la cérémonie (ibid., p. 59 note 45 ) ; il est intitulé «De Launebode qui aedificarit templum sancti saturnini ». Il

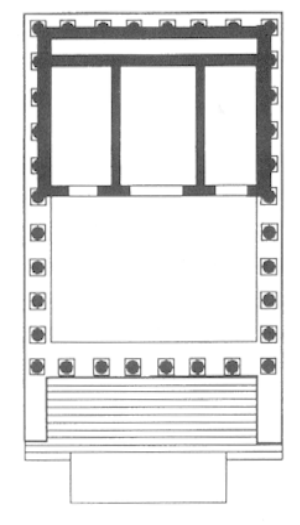

a

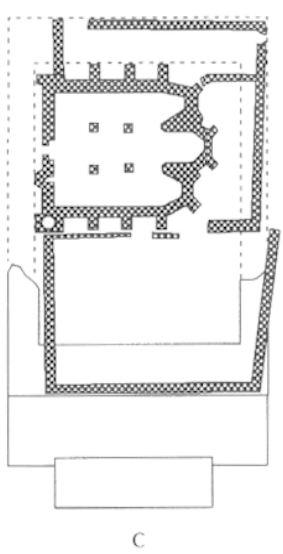

Fig. 25. Hypothèses de reconstitution : a, temple de Toulouse modélisé à partir des observations de terrain, du cadastre médiézal, des découvertes anciennes, des modèles théoriques et des sources; $b$, implantation de la basilica construite en 567 sur les ruines du temple; c, le Capitole et l'église Saint-Pierre-Saint-Géraud flanquée de la maison du prieur; d'après le cadastre de la fin du XV s. et les découvertes archéologiąues faites en 1992 (Boudartchouk, Arramond, 1993) (dessin H. Molet et L. Grimbert). 
s'agit du panégyrique de Launebode et sa femme, qui viennent de faire construire un "templum " sur le lieu même où Saturnin "reçut les liens ", c'est-à-dire en haut des marches du Capitole, locus qui, précise Fortunat, n'avait ćté ćtayé par l'honneur d'aucun temple (chrétien) ${ }^{8}$.

On notera l'ambiguité de l'expression " culmina sancta ", que l'on pourrait traduire par "édifice sacré " mais qui désigne aussi dans la langue classique un temple païen. On ne connaît rien de ce «templum» fondé sur les ruines du Capitole en 567. Peut-être a-t-il perduré durant le Haut Moyen Âge sous la forme d'un oratoire dédié à saint Pierre, compagnon de Saturnin, instigateur de sa mission dans l'hagiographie légendaire, depuis le VI's.

- Arnaud Arpadelle et l'église médiévale. Cet édifice réapparaît dans les textes au XII's., sous l'appellation " église Saint-Pierre-Saint-Géraud »; elle relève alors de l'abbaye d'Aurillac. Toutefois ses origines ne sont pas oubliées, puisqu'en 1296 le juriste toulousain Arpadelle, dans une glose des coutumes de la ville, écrit : "Les antiques consuls de Toulouse se réunissaient au lieu où est à présent l'église Saint-Pierre-Saint-Géraud; et en ce lieu appelé Capitole se trouvaient les idoles adorées par les paiens [...]. On peut lire dans la légende de saint Saturnin qui fut le premier évêque chrétien, qu'il fut conduit au Capitole et de même y fut condamné au supplice " (Martin-Chabot, 1918; Gilles, 1969, p. 158 159/Manuscrit B.N. Fd.Lt. ${ }^{\circ}$ 9187) ${ }^{9}$.

\footnotetext{
8. "Sed locus ille quidem, quo Sanchus vincula sumpsit

Nullius templi fultus honore fuit.

Launebodes enim, post saecula longa, ducatum

Dum gerit, intruxit culmina sancta loci. "

9. " [...] erant nisi tria Capitolia, videlicet in civitat" Romana et Constantinopolitana et civitate Tholose prout legitur in cranonicis et ab eorum sentenciis olim non appellabatur: Item Capitolimm dicebatur ille locus ubi judicabant homines ad aufferendum capud et sic quandogue ponebatur continens. pro contento. Verumptamen antiquitus consules Tholose congregabamt se in loco ubi modo est ecclesia sancti l'etri sanctique (ierardi et in illo loco erant ydole que colebantur per. Sarecenos et ille locus dicebatur Capitolium quia ibi judicabantur homines ad perdendum capud et ita invenitur in legenda sancti Saturnini qui fuit primus episcopus christianomum, qualiter fuit ductus ad Cappitolium et qualiter fuit judicatus per Capitolium. "

Ce texte avait fait l'objet d'une analyse critique de la part de M. I abrousse (1968, p. 422) qui considerait comme une " confusion" le rapprochement fait entre les Capitolenses ct le Capitolium. Cette affirmation doit être fortement nuancéc : Arpadelle évoque la fonction juridique du Capitole, qui a pu lui être suggérée par l'épisode du martyre de Saturnin, renforcée par sa connaissance possible des exécutions du
}

L'auteur, par cette référence historique, cherche à légitimer les pouvoirs des "Capitouls" (Consuls) de son temps, notamment en ce qui concerne leurs prérogatives judiciaires, sclon un mode de raisonnement courant à la fin du XIII"s.

I a localisation du Capitole semble avoir été oubliće peu après. Elle est en tout cas perdue au début du XVI s.

Malgré son caractère tardif, ce texte tend à prouver que le temple découvert place Esquirol est bien le Capitolium de Tolosa, sanctuaire qui est bien sûr au coưr de l'histoire de la cité antique.

\section{HYPOTHÈSES POUR UNE RECONSTITUTION DU SANCTUAIRE}

On a vu que l'emprise des fouilles n'a permis de reconnaitre que les substructions de l'escalier et d'une partic du pronaos. Il est néanmoins possible de se faire une idée du volume et des dimensions du podium.

\section{LE PLAN}

Un examen minutieux du cadastre médiéval a montré que l'église Saint-Pierre-Saint-Géraud et les limites parcellaires orthogonales qui l'entourent définissent quasiment $50 \%$ de l'emprise du podium, à l'emplacement théorique de la ou des cellae. On a vu que ce lieu de culte fut fondé en 567 sur les ruines du temple ( $c f$. infra, p. 234), peut-être selon un processus de réutilisation totale ou partielle des cellae, fréquent pour les temples (au forum boarium par exemple) et notamment les Capitoles d'Italic (Cagiano de Azevedo, 1940, p. 25; Vaes, 1989, p. 313-314). C'est aussi le cas de Capitolia d'autres provinces comme celui de Cirta à Constantine (Romanelli, tav. 1986) où l'église est entièrement " perchée " sur le podium, à Leptis Magna où un temple anonyme - peut-être

hau de la roche tarpéienne. Mais surtout, le juriste du XIII" s. fait ici étalage de son érudition dans une petite dissertation qui lui permet de faire ctat de ses connaissances historiques au sujet du Capitolium de Toulouse. En demière analyse, il est possible que, dans lesprit d'Arpadelle, Capitole ait été synonyme de forum au sens large, c'est-àdire lieu d'exercice du pouvoir public et done judiciaire. lauteur veutil dire que les consuls du XII"s., alors aut faîte de leur puissance judiciaire (peine capitale), se réunissaient sur le site du " (appitole ", lieu de pouvoir ancestral dont le souvenir subsistait, associé au martyre de Saturnin ? (Boudartchouk, Arramond, 1993, p. 24-25). 
un Capitolc - est entièrement oblitéré au V*s. par une église de plan basilical (Brouquier-Reddé, 1992, p. 79), mais aussi et surtout à Cologne où une église est bâtic sans doute vers 690 dans la cella centrale du Capitole alors que le temple est détruit depuis le V*s. Cette église sera ensuite agrandic au Moyen Âge pour recouvrir entièrement la superficie du temple (Trunk, 1991, p. 197 sq.). Enfin, N. Duval (1971, p. 296) note pour l'Afrique plusicurs exemples de temples transformés en églises où les cellae ont été respectées malgré la destruction du pronaos, alors que l'orientation originelle n'est pas toujours conservéc, l'église pouvant être bâtie en travers du temple (fig. 26).

À Toulouse, il est possible d'avancer une analyse structurelle précise si l'on considère attentivement le plan de l'église même dont l'ordonnance, à l'exception des deux absidioles gothiques à pans coupés, reprend sans doutc le plan d'une église du Haut Moyen Âge. Celle-ci était peut-ĉtre de type basilical si l'on se réfère au titre du poème de Fortunat tel qu'il est transcrit dans la table originclle des chapitres : "De Launebode qui aedificavit basilicam eius" (Fortunat, cf. Reydellet, 1994, p. 8, qui insiste sur le caractère fiable de cette table) ${ }^{10}$.

L'église Saint-Pierre-Saint-Géraud se dévcloppe d'est en ouest sur un peu plus des deux tiers de la largeur du podium, tandis que son emprise nord-sud est sensiblement en deçà de la limite nord du podium. Une emprise ainsi réduite pourrait traduire l'existence de subdivisions internes à la cella du temple, dans la mesure où les bâtisseurs du Haut Moyen Âge ont cu tendance à mettre à profit les maçonneries conservées, dans les cas de réutilisations de temples antiques (Vaes, 1989, p. 303). Ainsi, seules les cellae occidentale et centrale auraient été conservées pour bâtir l'oratoire du VI' s. Dans ce cas, le mur nord de l'église aurait pu être établi sur une maçonnerie parallèle à la limite septentrionale du podium, mais lćgèrement en deçà, dont la présence est attestée sur les Capitoles de Narbonne, Xanten, Cologne, Virunum, Gigthis, Timgad, Segni... Ceci n'est bien sûr qu'une hypothèse relative à la transition entre le temple antique et l'église médiévale (fig. 25). Toutefois, l'hypothèse de la réutilisation des maçonneries des cellae pour constituer la structure de l'église du Haut Moyen Âge pourrait être

10. Toutefois basilica est souvent employé à l'époque mérovingienne comme terme générique désignant un lieu de culte chrétien. confirmée par une observation ancienne, faite à l'occasion de travaux place de la Pierre où l'on parle de "robustes substructions en blocage de la chapelle StGéraud "(Malafosse, 1893), qui ne peuvent guère appartenir à la construction médiévale (Molet et al., 1994). C'est également à l'emplacement des cellae du temple que fut découverte en 1932 lors de travaux de démolition, dans un " terrain rapporté ", une "mosaïque de 60 ou $80 \mathrm{~cm}$ de long sur 50 de large [...] composée de petits
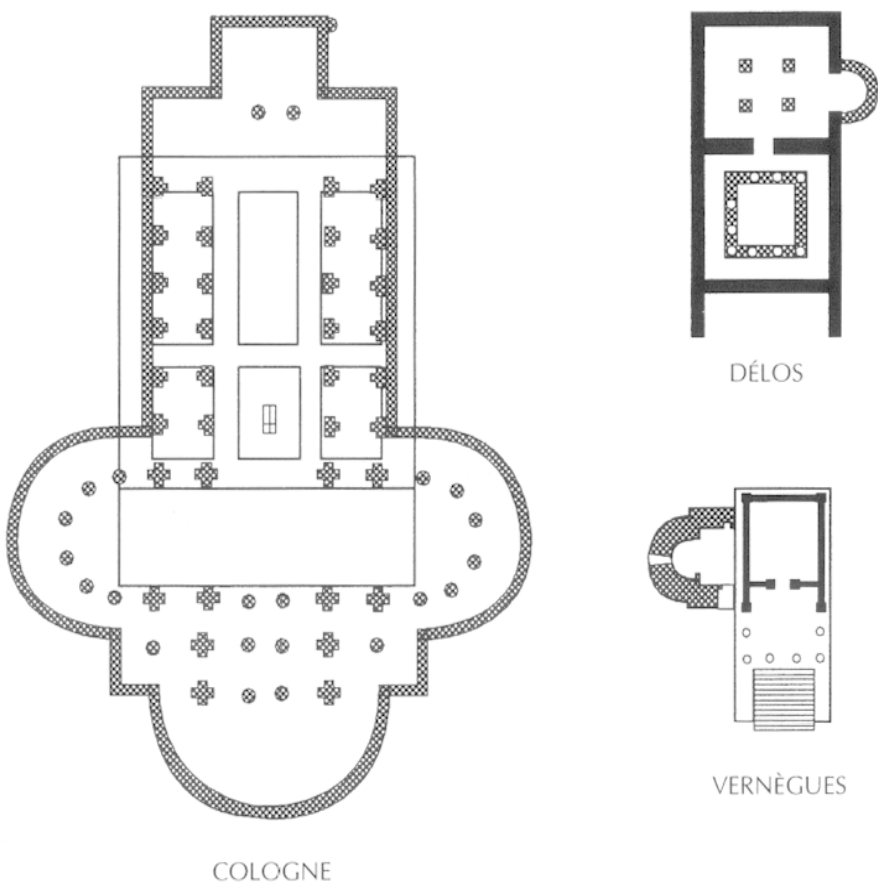

VERNÈGUES
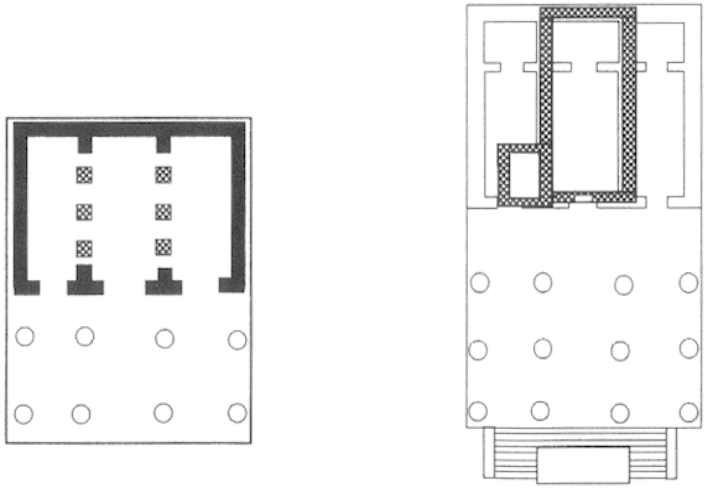

SORA

SEGNI

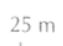

Fig. 26. Plans de sanctuaires pä̈ens christianisés d'après divers auteurs. Sora : sans échelle (dessin J.-L. Boudartchouk, I. Ilech et L. Grimbert). 
cubes de marbre [...] ornée d'une décoration de dessins triangulaires clairs sur fond sombre séparés par des entrelacs en câbles à trois rangs de cubes, blancs, gris, noirs ou roses"(Brousse, 1932, p. 146 sq.). La photo de cette mosaïque disparue permet d'y voir une ouvre antique, peut-être tardive.

Ces indices architecturaux vont dans le sens de la présence d'un temple à trois cellae, dont on sait qu'ils caractérisent les Capitoles de la période républicaine et des débuts de l'Empire, jusqu'à l'époque flavienne comprise en Italie (Bianchi, 1950, p. 370-376). Ainsi le temple de la place Esquirol pourrait répondre aux trois critères retenus par M. Todd (1985, p. 57) pour l'identification d'un Capitolium : haut podium et position dominante, pronaos profond et tripartition de la cella (les deux derniers critères demrandant bien sûr ici une confirmation archéologique).

Dans cette hypothèse, la limite nord du podium serait indiquée par la ligne de force située immédiatement audelà de la façade nord de l'église. Ceci permet de reconstituer un podium d'environ $27 \times 35 \mathrm{~m}$, soit près de $90 \mathrm{x}$ 120 pieds romains de $29,6 \mathrm{~cm}(3 / 4 \times 1$ actus $)$; dimensions qui correspondent à celles du temple dit " du Cigognier " à Avenches, mais aussi à plusicurs Capitoles du monde romain (cf. supra, p. 220). Si l'on tient compte de l'escalier situé en avant du pronaos, on obtient une longueur totale de $43 \mathrm{~m}$. Ces dimensions font du temple de la place Esquirol un des plus grands temples de type classique en Gaule, derrière le Capitole de Narbonne et le présumé sanctuaire municipal du culte impérial de Iyon (Lasfargues, Le Glay, 1980).

L'épaisseur respective du mur de façade $(3,80 \mathrm{~m})$ ct des murs latéraux $(3,20 \mathrm{~m})$ du soubassement du podium incite à voir dans ce temple un pseudo-périptère. Une restitution plus précise du plan doit être avancéc avec prudence; toutefois il est possible d'énoncer quelques hypothèses, à l'aide d'exemples comparatifs et des règles théoriques exposées par Vitruve.

Concernant le nombre de colonnes en façade, le caractère imposant de celle du temple d'Esquirol $(27 \mathrm{~m})$ permet d'envisager un sanctuaire hexastyle ou octostyle, doté d'une seule rangée de colonnes en façade, si l'on se réfère à la puissance des substructions correspondantes trop faible pour soutenir deux rangées de colonnes comme à Narbonne (Perret, 1956, p. 10).

Nous avons pu estimer le diamètre d'une colonne entre 1,20 et $1,30 \mathrm{~m}$ ( $c f$. supra, p. 208). Partant de ce module, nous avons tenté de lui appliquer les "species" décrits par Vitruve (III, 3, 1), caractérisant différents rythmes de façades (Vitruve, cf. Gros, 1990b, p. 99-101). Il apparaît que les modèles théoriques élaborés à partir d'une façade hexastyle s'accordent mal avec les dimensions du podium. En revanche, une façade octostyle de type pycnostyle, " temple dans l'entrecolonnement duquel peut être inséré l'équivalent d'un diamètre et demi de colonne " (Vitruve, III, 3, 1), conviendrait bien au plan des substructions découvertes ou supposées. Ia façade occuperait ainsi 24,05 m (huit colonnes de $1,30 \mathrm{~m}$ de diamètre séparées par des espaces de 1,95 m). En gardant le même module, on obtient 11 colonnes latérales, se développant sur $33,80 \mathrm{~m}$.

Un schéma légèrement différent est envisageable, à partir de colonnes de $1,20 \mathrm{~m}$ de diamètre (soit près de 4 pieds) disposées selon un rythme systyle, c'est-à-dire deux diamètres de colonnes dans l'entrecolonnement (Vitruve, III, 3, 1). Dans cette optique, la façade octostyle occuperait $26,4 \mathrm{~m}$ et les colonnes latérales seraient au nombre de dix, ce qui, avec des entrecolonnements identiques, occuperait $33,6 \mathrm{~cm}$ (fig. 25).

Le premier plan $(8$ colonnes en façade, 11 colonnes latérales) rappelle celui du Capitole de Narbonne, le second se rapprochant plutôt de celui de Cologne (Hellenkemper, 1975) ; la plupart des temples ayant une largeur comparable à celui de Toulouse dont nous avons pu étudier le plan présentent une façade octostyle : le grand temple d'Orange, le Cigognier à Avenches, le petit temple de Cirta ou le temple d'Hercules Victor à Tivoli.

En dernière analyse, il est bien sûr délicat de reconstituer avec précision l'emprise de la cella; mais si l'on retient l'hypothèse de sa réutilisation pour construire l'édifice qui deviendra l'église Saint-Pierre-Saint-Géraud au Moyen Âge, on remarque qu'elle a pu occuper environ $50 \%$ de la surface du podium, dont le rapport longueur/largeur, 4/3, est proche de $5 / 6$ correspondant à la description du temple toscan à trois cellae décrit par Vitruve (IV, 7, 1) (cf. supra, p. 220).

\section{L'ÉLÉvation}

Plus encore que le plan, l'élévation doit être cnvisagée avec prudence. On peut toutefois avancer un ordre de grandeur, à l'aide des prescriptions de Vitruve énoncées dans son livrc III. Bien sûr, il s'agit d'un modèle théorique dont la mise en application effective n'a été que 
très rarement observéc. C'est pourquoi ce modèle doit être tempéré et complété par des données architecturales issues de l'étude d'édifices conservés du $I^{*}$ s. Concernant le temple de la place Esquirol, on dispose pour bâtir ce modèle du dianètue d'un fût de colonne à sa base soit approximativement $1,30 \mathrm{~m}$.

L'addition des données issues de ce modèle permet d'estimer la hauteur totale approximative minimale du temple de la place Esquirol à 25-26 m, soit légèrement inférieure à la largeur du podium ${ }^{\prime \prime}$.

\section{LE CAPITOLE ET I A CITÉ ANTIQUE}

\section{L'ENVIRONNEMENT DU TEMPLE ET LE FORUM PROBABLE DE TOLOSA}

I es données recucillies lors de l'intervention archéologique, complétées par celles issues de fouilles ou

11. La hauteur du podium derait être importante au vu de l'escalier monumental, prolongeant de $8 \mathrm{~m}$ le pronaos, et de la puissance remarquable de ses fondations. Vitruve ne domnant pas d'indications sur la hauteur théorique du podium, nous avons pris comme référence l'escalier monumental du temple dit " du Cigognicr" (Bridel, 1982, p. 38 sq.), légèrement moins développé que celui de Toulouse, pour un podium de dimensions comparables. Fn gardant des proportions semblables, on aboutirait pour Toulouse à un podium d'une hauteur minimum d'environ $4 \mathrm{~m}$, soit un peu plus que la hauteur envisagée par V. Perret pour le Capitole de Narbonne, tout en sachant que des (appitoles de dimensions comparables comme ceux de Virunum, Cirta et Thamugadi ont des podia de $3,4,5$ ) et $6 \mathrm{~m}$ de haut (Castagnoli, 1959, p. 329-330 ; Barton, 1982, p. 328-330).

I'céevation theorique d'une colonnade pycnostyle corinthienne, chapiteau compris, etant de 10 modules $2 / 3$ (Gros, 1990b), on obtient pour une colonne d'un diamètre de $1,30 \mathrm{~m}$ une hauteur totale de $13,87 \mathrm{~m}$. En gardant le même module, toujours selon Vitruve, on obtient une hauteur de base attique de $0,65 \mathrm{~m}$ pour un chapiteau corinthien de $1,30 \mathrm{~m}$ de haut (III, 5, $2 ; \mathrm{IV}, 1,1)$.

Pour l'entablement, si l'on tient compte du modele préconisé par Vitruve pour les plus hautes colonnes ioniennes dont il fait mention (III, 5, 8), l'architrave a pu avoir une hauteur de $1,16 \mathrm{~m}$, surmontée par une frise décorée de $1,45 \mathrm{~m}$ (III, 5, 11). La corniche pourrait être d'une hauteur voisine de $1,05 \mathrm{~m}$ (III, 5, 12 ; Gros, 1990b, p. 191 sq.). Ceci permettrait de situer la hauteur approximative de l'entablement à $3,66 \mathrm{~m}$. En ce qui concerne le fronton, les proportions suggérées par Vitruve (hauteur du fronton égale à $1 / 9^{\circ}$ de la largeur totale de la corniche en façade (III, 5,12 ) ne sauraient convenir à un sanctuaire de type romain du $I^{\mathrm{er}} \mathrm{s}$. de notre ère (Gros, 1990b, p. 188); une relation de 1/6, voisine de celle de la "Maison carrée " de Nîmes, serait peut-être plus à même de fournir une idée de la hauteur du fronton du temple de Toulouse. Si l'on prend pour base une largeur totale de la frise de $25 \mathrm{~m}$, on obtient un fronton de $4,16 \mathrm{~m}$ de hauteur maximum. découvertes anciennes et associées à l'étude du cadastre médiéval et des archives, permettent d'envisager une restitution sommaire du centre monumental de la cité, qui semble se développer au sud du temple. Si la restitution sur sa face nord, c'est-à-dirc ccllc du Capitole, ne pose guère de problèmes, en revanche une approche du forum proprement dit, séparé du secteur du temple par le decumanus maximus probable, est nettement plus aléatoire. Tout au plus peut-on suggérer un ordre de grandeur et une structuration grossière de l'ensemble.

\section{LA ZONE DU TEMPLE}

I.es trois axes antiques délimitant le secteur du sanctuaire sont connus. I e decumanus marquant la limite nord de l'ensemble suit plus ou moins le tracé de l'actuelle ruc Peyras, appelée "Carriera de Peyranis " en 1339 (rue des Grosses-Pierres, Archives départementales de Haute-Garonne 4(; 39). Cet axc est connu grâce à un égout antique (Iabrousse, 1968, p. 298; Baccrabère, 1977 , p. 32).

I a ruc bordant le centre monumental à l'ouest n'est autre que le cardo maximus, connu depuis le XVII' s. (I abrousse, 1968, p. 293-295 ; Baccrabère, 1977, p. 29), actuellement matérialisé par les rues Saint-Rome, des Changes et des Filatiers. Une fouille effectuéc en 1992 a confirmé cette aturibution (Vidal, Jaubert, 1993, p. 15; Filippo, 1993a, p. 70). Enfin l'axe bordant le côté oriental du portique est un cardo secondaire dont l'existence était soupçonnée par la présence d'égouts antiques rue Baronie et place Rouaix, qui se prolongeaient jusqu'à hauteur des rues Fleurs et Nazareth (I abrousse, 1968, p. 297 ; Baccrabère, 1977 , p. $24-25$ et 31 ). La fouille du parking Esquirol a confirmé l'existence de ce cardo, fondé dans la première moitić du $\mathrm{I}^{\mathrm{tr}} \mathrm{s}$. et utilisé jusqu'au $\mathrm{V}^{*}$ s. Il longe le mur extérieur du portique (Arramond, Boudartchouk, 1993, p. 73).

C'est à l'intérieur de ce périmètre que se situe le secteur cultuel du forum. I e temple est placé à équidistance des deux cardo. De même, les deux sections de portique reconnues sont parfaitement symétriques ; l'une longe le cardo maximus, l'autre le cardo secondaire. Nous avons donc affaire à une rationalisation de l'espace par rapport au temple, qui constitue l'élément central. Si l'on compare cette organisation avec des plans de fora suffisamment connus comme à Augst, Virunum, Benevagienna, Luni où le Capitole est cntouré d'un porticus triplex (Gros, 
1990a, p. 41-42), Minturnae, Verona où un portique « en pi " entoure le Capitole (Cavalieri-Manasse, 1990, p. 597), etc., on peut supposer que le retour nord du portique se situe à une distance comparable à celle séparant l'aile sud du portique du côté sud du podium, dans un souci de symétrie.

Cette hypothèse appliquée à la place Esquirol ferait passer la partie septentrionale du portique sur une ligne de force du cadastre médiéval, à hauteur de deux " perriers "mentionnés en 1507 (Archives départementales de Haute-Garonne 1G 1010-15), terme qui peut, dans le contexte toulousain, matérialiser la présence de structures antiques servant de carric̀res. Une telle restitution est donc vraisemblable. Dans cette hypothèse, le temple est entouré sur trois côtés par un portique à colonnade médiane de $10 \mathrm{~m}$ de large dont la paroi interne est implantée à $19 \mathrm{~m}$ du podium à l'est et à l'ouest et environ $35 \mathrm{~m}$ au nord.

\section{LE DECUMANUS MAXIMUS}

I a limite sud de l'area du temple est mal connue; toutefois, l'examen rapide de ce que l'on sait de la trame antique de Toulouse (Labrousse, 1968, chap. VIII ; Baccrabère, 1977, p. 21-32) montre qu'un decumanus devait passer à peu de distance du temple. I ces auteurs hésitaient néanmoins sur l'itinéraire précis de l'axe antiquc. Cette voie, dont le tracé a été restitué récemment par D. Cazes dans ses grandes lignes, venait de la Garonne au débouché de l'aqueduc antique dit de la "Reine Pédauque ", laissant sur sa gauche le théâtre, pour traverser le sud de la zone du temple, avant de se diriger vers la porte Saint-Étienne, laissant sur sa droite le groupe cathédral de l'Antiquité tardive (Cazes, 1988, p. 64). Par sa situation topographique et son rôle économique, cet axe a toutes les chances d'être le decumanus maximus de Tolosa. On peut invoquer à l'appui de cette hypothèse une série d'arguments tirés d'observations anciennes et de fouilles ponctuelles, associées à l'étude du cadastre médiéval (étude H. Molet).

D'ouest en est, le decumanus aurait pu avoir le trajet suivant : venant de la place Assezat, où il serait passé entre le théâtre antique ct le débouché de l'aqueduc, il aurait emprunté le tracé de l'ancienne rue Succurion, devenue rue des Marchands à la fin du Moyen Âge.

En effet, cette carriera vocata succurionis (1323-Archives municipales de Toulouse I. I. 10) aboutit au sud-ouest de l'escalier monumental du temple. Or, dans l'axe de cette rue (angle de la rue des Marchands et de la place de la Trinité) a été découvert au XVIII" s. un égout, "issue ou puids de deux cannes de profondeur $(2,6 \mathrm{~m})$, et il y a un acqueduc, lequel acqueduc a hauteur d'homme ou environ, lesdites issue et acqueduc sont en tout bâtis en briques " (Archives municipales de Toulouse DD 258, Cussanne). Ceci pourrait constituer l'égout de l'axe antique, qui paraît être décrit dans un document de 1180 (Limouzin-I amothe, 1932, p. 296-297) réglant l'écoulcment des eaux de la ville ${ }^{12}$.

Ce decumanus, au débouché de la rue Succurion, serait donc passé au sud de l'escalier du temple, longeant certainement le mur orienté est-ouest de la structure observée par M. Vidal et B. Marty ( $c f$. infra, p. 229). Cette hypothèse permet de situer approximativement le retour sud du portique du temple qui ne devait pas manquer de longer l'autre bas-côté du decumanus, entre 35 et $45 \mathrm{~m}$ au sud de l'escalier monumental, ce qui paraît être confirmé par l'examen du cadastre médiéval. Ceci permet de circonscrire approximativement la surface occupéc par le temple et son portique dans un rectangle de $130 \times 90 \mathrm{~m}$ environ. Le temple serait alors exactement au centre de ce rectangle.

Ensuite, l'axe antique aurait emprunté l'ancienne impasse Bertrand-Davini-de-Rouaix (XIV" et XV's.), prolongé vers l'est par une ligne de force du cadastre médiéval, en direction du nord de la place Saint-Étienne où sa présence paraît attestée par l'archéologie.

Ie decumanus maximus provoquerait donc une bipartition du forum en le traversant dans sa largeur, délimitant l'aire sacrée de l'aire " profane ". On peut observer des partitions semblables notamment à Ostie, Brescia, Virunum, Nyon et Benevagienna. Toutefois, des obstacles empêchant la circulation des véhicules dans le périmètre du forum peuvent avoir existé (Blutstein-Latremolière, 1991, p. 51-54 ; Balty, 1993, p. 21 sq.).

\section{LE FORUM}

Une telle disposition semble être confirmée par les fouilles menées par M. Vidal et B. Marty en 1982 (Vidal,

12. "Aque que veniunt per carrariam P'oncii Bertrandi currant versus pontem veterem ante domum Petri de Sancto Romano et Arnaldi Otomis et cadant in Caronnam inter capud pontis et solerium de Alcotomeriis. l... I Aque de cornu domus Petri de. Roais qui fuit currant versus pontem veterem et cadant in Garonnam l....." 
1987). À cette occasion avait ćté mis au jour, dans une cave située au 11 rue des Tourneurs, l'angle d'un bâtiment dont les techniques de construction rappellent le temple et surtout le portique (moellons liés au mortier). Cette structure, qui suit l'orientation du quadrillage antique, se compose de deux murs formant un angle droit, à l'est desquels se développe un massif de maçonnerie. Le mur nord-sud, dont la façade orientale est peutêtre rythmée de pilastres, longe le cardo de la rue des Tourneurs, dont les niveaux tardifs ont été aperçus à cette occasion (fig. 27). Ce mur se situe dans le prolongement du portique fouillé en 1993. Le mur est-ouest ferme la structure face à l'area du temple. Or c'est précisément au nord de ce mur que passe le tracé théorique du decumanus maximus. Le site a par ailleurs livré les fragments d'une base de colonne de marbre monumentale d'ordre corinthien (Baccrabère, 1984, p. 126 sq.). On scrait donc en présence d'un bâtiment public de grandes dimensions longé par le cardo secondaire et le decumanus maximus. Si l'on examine sa position par rapport au temple à la lumière d'exemples comparatifs, il devient très probable que nous soyons en présence de l'angle nord-est du forum proprement dit, séparé du secteur du temple par le decumanus maximus. Dans cette hypothèse, l'important massif de maçonnerie présent à l'est du mur nord-est pourrait traduire l'existence d'une entrée monumentale, comme cela est le cas à Augst. Ce mur orienté est-ouest pourrait se poursuivre vers l'ouest jusqu'à la place Rouaix, à la jonction des rues des Filatiers et des Marchands où l'on a aperçu en 1960 « un mur de nature très compacte composé d'un blocage de galets roulés de $1,50 \mathrm{~m}$ environ d'épaisseur, d'orientation estouest "(Baccrabère, 1964, p. 96 note 77). Dans cette hypothèse, on obtiendrait la largeur minimum du forum, soit plus de $90 \mathrm{~m}$.

Dans la même optique, le mur nord-sud observé par M. Vidal semble se poursuivre vers le sud puisqu'en 1903, une tranchée fut ouverte place Rouaix, dans l'axe de la rue Alsace-Lorraine (Lanes, 1903, p. 223-224) et l'on y découvrit des "substructions très anciennes, dont il ne reste que quelques pans de mur [...]. Le fond, sur un mètre d'épaisseur à l'aplomb de la tranchée et à partir de $0,50 \mathrm{~m}$ du fond est en maçonnerie de cailloux et de ciment très dur. Dans les matériaux, on a trouvé des fragments de pierre de taille et de marbre, des débris de colonne en pierre ayant environ $0,60 \mathrm{~m}$ de diamètre et des fragments de caniveaux en pierre [...] beaucoup de

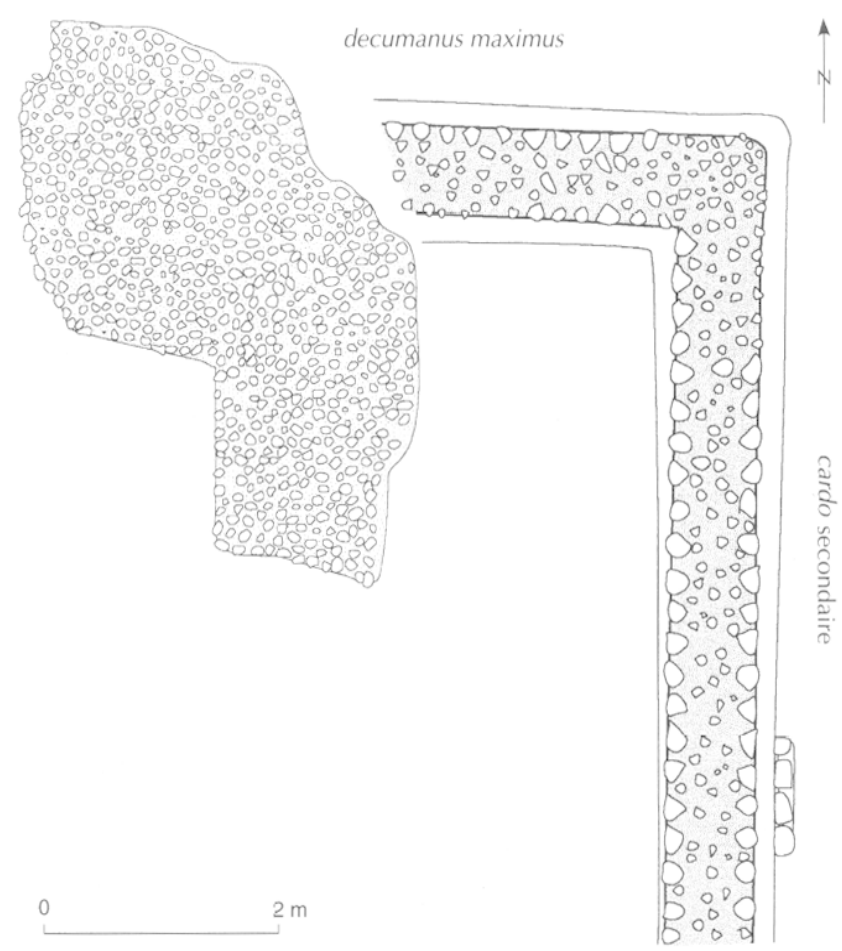

Fig. 27. Angle du bâtiment découvert lors des fouilles Vidal et Marty en 1982, qui constitue sans doute l'angle nord-est de l'area du forum (d'après Vidal, 1987 complété).

fragments de tuiles et de poterie noire, morceaux d'amphore, un débris de colonne en marbre vert qui avait environ $0,80 \mathrm{~m}$ de diamètre ". Les structures (puissant mur en maçonnerie) ainsi que les nombreux débris architecturaux rappellent ceux des fouilles Vidal et Marty.

En janvier 1903, une tranchée perpendiculaire fut faite place Rouaix : elle livra " des poteries, quelques tuiles, trois ou quatre pierres appareillées comme celles du Jardin du Capitole... » (Lanes, 1903, p. 227), c'est-àdire le petit appareil calcaire employé place Esquirol et rue des Tourneurs.

L a surface totale du forum est difficile à appréhender, en raison de l'absence de fouilles. Toutefois il est possible de le circonscrire entre trois axes : le decumanus maximus, le cardo maximus (rue des Filatiers) et le cardo secondaire (rue des Tourneurs, puis rue du Languedoc). L'axe fermant le forum au sud pourrait être un decumanus secondaire dont les actuelles rues Jouxt-Aigues et Maletache épousent la direction. Des égouts vraisemblablement antiques ont en effet été découverts rue JouxtAigues le long de cet axe, dont les limites parcellaires 


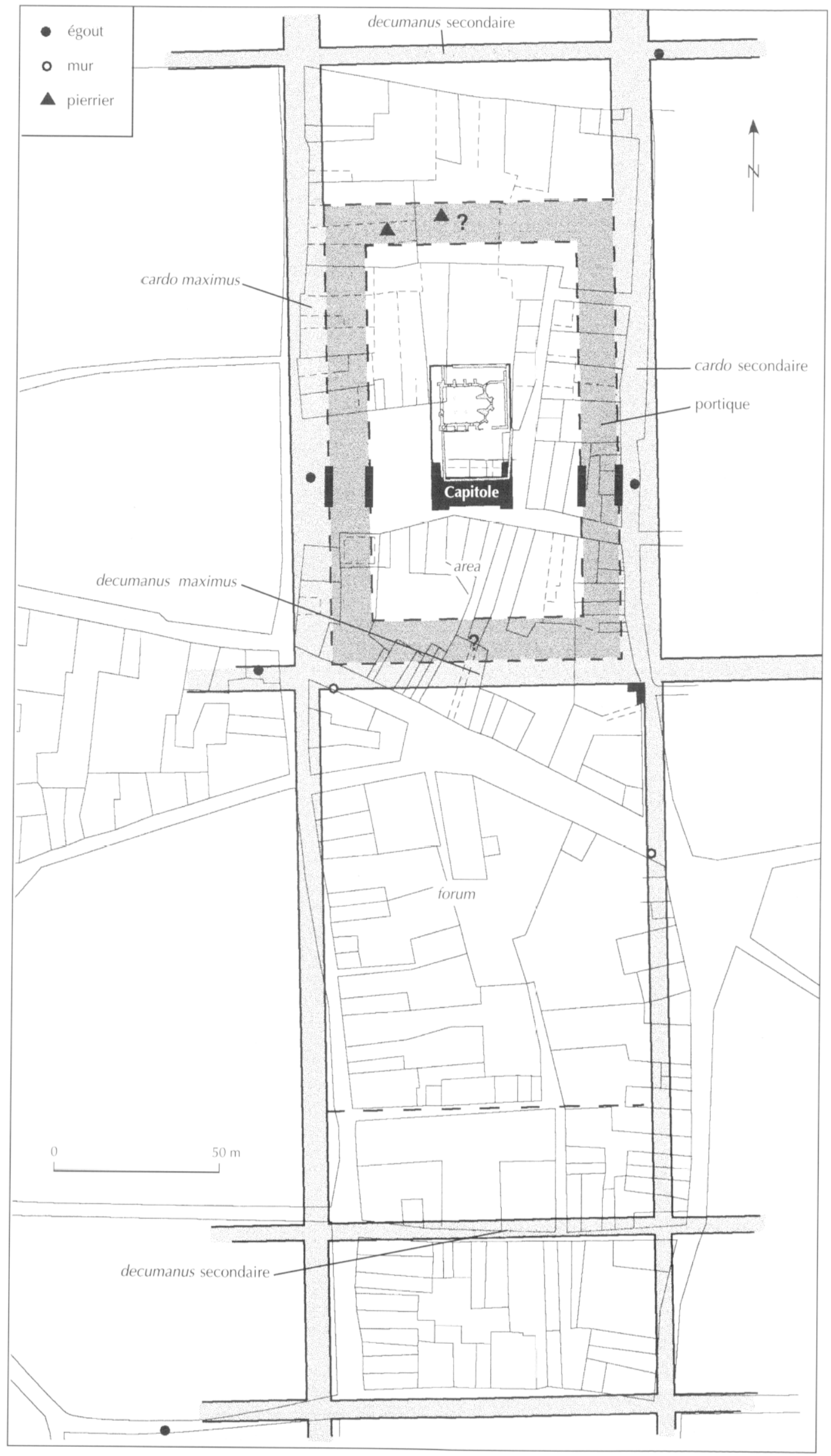

Fig. 28. Hypothèse de topographie du forum de la cité d'après les fouilles récentes, les découvertes et les données d'archives (fond de plan : cadastre du XV"s., H. Molet, J.-L. Boud(crtchouk et L. Grimbert). 
maintiennent la direction à l'est et à l'ouest (Baccrabère, 1977, p. 33). Si l'on retient cette hypothèse, le forum proprement dit serait circonscrit dans un rectangle d'environ $150 \times 100 \mathrm{~m}$, c'est-à-dire une longueur légèrement supéricure à celle de l'insula du Capitole. On rencontrera des proportions comparables sur les fora d'Augst, Virunum, Benevagienna, et dans une moindre mesure à Luni, Vérone, Feurs, Nyon.

Dans ces cas, le forum présente une structure bipartite, la basilique étant implantée transversalement à l'axe du forum, à l'opposé du temple.

Si l'on retient ce schéma pour Toulouse, il faudrait situer la basilique à l'extrémité sud du rectangle précédemment défini, auquel cas la rue des Quatre-Billards, orientée sclon le quadrillage antique, pourrait fournir une trace fossile intëressante. Il convient bien sûr de rester extrêmement prudent, ceci ne constituant qu'une restitution théorique, que ne confirme pour l'instant aucune découverte archéologique.

Ce que l'on connaît du forum de Toulouse, à savoir la zone du temple et un angle de l'esplanade centrale, complété par une approche empirique de son emprise, nous incite à le rapprocher de plans " attestant l'intégration totale des différents éléments de forum " (temple, esplanade, basilique), selon un modèle peut-être issu de l'évolution fonctionnelle des fora de l'Italie du Nord à l'époque républicaine (Balty, 1993). Des plans de ce type apparaissent en Gaule, peut-être dès l'époque de Néron, en tout cas dans le courant du $\mathrm{I}^{\mathrm{er}} \mathrm{s}$. (cf. Goudineau, in : Duby éd., 1989, I, p. 272 sq.). En tout état de cause, les dimensions totales du forum de Toulouse (temple compris) semblent importantes : environ $100 \times 300 \mathrm{~m}$ (fig. 28).

\section{CAPITOLE ET STATUT DE LA CITÉ}

La construction, peut-être durant la seconde moitié du I ${ }^{\mathrm{rr}}$ s., d'un temple probablement dédié à la triade capitoline, entouré d'un puissant portique et constituant certainement le sanctuaire majeur du forum de Tolosa, revêt une signification particulièrement forte au regard de l'histoire de la ville antique. En effet, à la suite de A. Castan, U. Bianchi puis F. Castagnoli pour l'Italie et I. Barton pour l'Afrique ont montré que, à l'origine, la construction d'un Capitolium est l'apanage exclusif des cités possédant le titre de colonia, qu'il s'agisse de colonies militaires ou honoraires (Castan, 1886; Bianchi,
1973, p. 63; Castagnoli, 1959; Barton, 1982). Néanmoins si cettc affirmation est pleinement vérifiable en ce qui concerne l'Italic républicaine et tardo-républicaine, il apparaît que sous l'Empire, des cités de condition juridique inférieure ont pu, elles aussi, obtenir l'autorisation d'édifier un Capitole. Ce constat est particulièrement évident en Afrique (Barton, 1982). Cependant, certaines cités ne se sont dotées que tardivement d'un Capitole bien qu'elles en aient eu la possibilité juridique (Février, 1975, p. 132).

Malgré la concurrence du culte impérial naissant, U. Bianchi (1973, p. 74) note la construction de Capitolia dans des colonies d'époque augustéenne comme Vérone ct Brixia. Concernant le début de l'Empire, M. Todd (1985), après avoir remarqué la construction de Capitoles cn Gaule cisalpine après 89 avant notre ère (op. cit., p. 59), souligne le rôle encore important de ces édifices sous l'Empire (Brixia, Ostie, op. cit., p. 61), alors que les fondations s'échelonnent à travers les provinces du $\mathrm{I}^{\mathrm{r}}$ au III's. (ibid., p. 64-65). L'auteur remarque que si les communautés se dotant d'un Capitole sont généralement des colonies, leur construction marque souvent une ascension dans leur statut juridique (ibid., p. 57).

La période à partir de laquelle des communautés autres que celles possédant le titre de colonia ont commencé à édifier des Capitoles est difficile à appréhender. Selon A. Castagnoli (1959, p. 328) cette transition est à situer au II' $s$. de notre ère. Si l'on se réfère à ses conclusions, à Toulouse l'hypothèse d'un Capitole construit durant la seconde moitié du Irr $s$. impliquerait donc la possession préalable par la cité du titre de colonia.

Bien sûr des historiens ont tenté depuis longtemps d'appréhender la date d'accession à ce statut. M. Labrousse (1968, p. 488 sq.) remarque que Toulouse, citée comme un des oppida latina (relevant donc du droit latin) par Pline l'ancien (Histoire naturelle, III, 37) est en revanche qualifiée de colonia par Ptolémée dans sa Géographie (II, 10, 6-4), manuscrit achevé vers 130 de notre ère ${ }^{13}$.

Si l'on se réfère à ces deux textes, le titre de colonie aurait été acquis entre les années 70 et 120 . Néanmoins, le texte de Pline s'inspire d'Agrippa et renvoie donc en

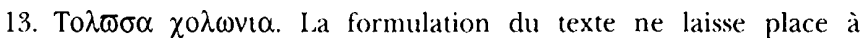
aucune ambiguité : il s'agit bien d'une colonie romaine, au même titre que Narbonne et Nîmes. Si les différents manuscrits offrent des variantes orthographiques du nom de la ville, le titre est invariablement répété. 
partie à une réalité plus ancienne. Ceci a permis à certains historiens de mettre en doute le témoignage de l'auteur au sujet du statut de Toulouse. C'est pourquoi l'on s'accorde à situer pour la cité l'obtention du statut de colonia quclque part entre le règne d'Auguste et celui d'Hadrien.

J.-M. Pailler (1988), s'appuyant sur le cursus d'un notable toulousain élevé à l'archontat éponyme d'Athènes, attribue à Domitien (81-96) l'octroi du titre de colonie permettant la construction d'un Capitole. On rappellera que cet empereur était attaché aux cultes traditionnels et notamment à la triade capitoline (instauration des Jeux capitolins, reconstruction du Capitolium de Rome, dévotion à Jupiter Optimus Maximus et Minerve...). Les résultats de la fouille du parking Esquirol ne vont pas à l'encontre de cette analyse, en situant dans la seconde moitié du $\mathrm{I}^{\mathrm{er}}$ s. la construction du Capitole, privilège découlant du titre de colonie sans doute fraîchement acquis par une faveur impériale, peut-être sous Claude, Néron, Vespasien, Titus ou Domitien.

Au-delà de la problématique de la colonic, la présence d'un Capitolium, temple du culte municipal et du culte romain par excellence, d'un type rare en Gaulc et même en Narbonnaise (Bianchi, 1949, p. 413; Gros, 1986, p. 112), traduit le haut degré de romanisation de la cité et de ses habitants dont le souvenir perdurera jusqu'au Moyen Âge à travers l'appellation « Rome de la Garonne».

Enfin, il est naturel que ce soit le Capitole de la cité, symbole de l'adhésion de celle-ci à Rome, à ses lois et à ses dieux, qui ait joué un rôle central lorsque l'on chercha à exorciser les menaces pesant sur l'Empire, comme le fit Dèce à travers son édit de 250 en demandant à tous un témoignage de piété politique impliquant une adhésion à l'Empire.

En cette occasion, le refus obstiné de l'évêque Saturnin, son impiété publique, ne pouvaient manquer de provoquer la colère du peuple, initiateur du châtiment sans appel qui a suivi.

\section{AUTOUR DE LA DESTRUCTION DU CAPITOLE}

\section{L'ABANDON ET LA DESTRUCTION PARTIELLE DU V V'}

Le caractère méthodique et rapide de la destruction du temple à l'extrême fin du IV's. ou au début du V's. nous a conduits à écarter l'hypothèse d'une destruction accidentelle ou liée à un événement ponctuel pour interroger la législation impériale chrétienne régissant la destinée des temples païens, conservée dans le Code théodosien.

La destruction systématique avec récupération des matériaux des sanctuaires principaux des cités a été souvent constatée lors des fouilles récentes, elle survient souvent entre la fin du IV" et le début du V's. On peut citer les exemples de Lyon au "Verbe incarné " (Iasfargues, Le Glay, 1980, p. 400) ; Cordouc (Jimene\%Salvador, 1991) ; Vérone où l'abandon du secteur du temple intervient à la fin du IV's. avant une destruction radicale au VI's.; de nombreux fragments architectoniques sont alors remployés (Cavalieri-Manasse, 1990, p. 594); Pola où l'abandon et le démantèlement du temple a lieu entre le V'et le VII"s., alors que des blocs provenant du sanctuaire sont remployés au VI's. dans une basilique chrétienne voisine, sur le forum (Matijasic, 1990, p. 643-644).

Deux édits du Code théodosien sont particulièrement intéressants, dans un contexte où l'interdiction de tout sacrifice et la fermeture des temples à la suite des édits de 341 et 346 (C.T. XVI-10-2 et XVI-10-4) ont certainement engendré déprédations et appropriations. Deux édits d'Honorius, rendus en 399 et 400, concernent la préservation des bâtiments ${ }^{14}$. L e premier vise à la conservation des monuments publics urbains, l'autre s'applique plus spécialement aux temples. Si les cultes païens sont interdits, les temples, qui demeurent du domaine public (ils appartiennent au fisc of. C.T. XII-1-60), ne doivent pas faire l'objet de déprédations.

Une autre mesure, prise en 401 (C.T. XV-1-41), décrète que les temples désaffectés doivent être entretcnus par les décurions; il est interdit d'aliéner les matériaux les constituant, sauf si le temple n'est d'aucun usage et ne contribue pas à la parure de la cité; dans ce cas le gouverneur provincial peut décréter une autorisation de cession, le produit de la vente revenant au Trésor

14. "Sicul sacrificia prohibemus, ita volumus publicorum operum ornamenta seruari, ac ne sibi aliqua auctoritate blandiantur qui ea conantur evertere... " (C.T. XVI-10-15).

"Aedes inlicitis rebus vacuans nostram beneficio sanctionum ne quis conetur evertere [...]. Decerninus enim ut aedificiorum quidem sil integer status. Si quis vero sacrificio fuerit deprehensus, in eum legibus vindecetur; depositis sub officio idolis, disceptatione habita, quibus etiam nunc potuerit cultum vanae superstitionis impendi. "(C.T. XVI-10-18). 
municipal (cité par Lepelley, 1979, p. 349). C'est donc officiellement à partir de 401 que l'Église a pu acquérir des temples et les transformer en basiliques; en Afrique, ce phénomène est demeuré rare, les anciens Capitoles étant plutôt affectés à des usages profanes (ibid., p. 354).

I.es sanctuaires urbains, bien qu'inusités en tant que lieux de culte "païen ", sont donc protégés par l'empereur en 400 .

Or, en 408, Honorius rend un édit inspiré par la législation de l'Orient stipulant que les autels doivent être détruits partout; les temples situés sur des propriétés particulières doivent être impérativement détruits ; les autres - dans la catégorie desquels entre le Capitole de Toulouse - sont adjugés au fisc et affectés si possible à d'autres usages. Dans tous les cas les statues doivent disparaitre ${ }^{15}$.

Un édit similaire mais plus détaillé est publié en 415 (C.T. XVI-10-20). Il accorde encore un répit aux temples urbains.

Mais, en 426, Théodose II stipule : « Nous voulons que les temples et sanctuaires encore intacts soient détruits par l'ordre de l'administration, que la souillure en soit effacée par l'érection du signe vénérable de la religion chrétienne. "Les contrevenants sont punis de la peine capitale ${ }^{16}$.

Si l'on s'en tient à ces textes, c'est donc entre 401 et 425 que l'on peut envisager la destruction systématique du temple, à l'instigation des autorités municipales (en considérant bien entendu que cette législation ait été appliquée en Narbonnaise même après le foedus de 418).

Un autre corpus de textes juridiques est fourni par le Bréviaire d'Alaric rédigé dans le royaume wisigoth en 506 et qui restera en usage durant une partie du Haut Moyen Âge (Rouche, 1979, p. 48). Ce Bréviaire, un abrégé des lois du Code théodosien, contient une série de dispositions pouvant s'appliquer au temple de la place Esquirol. Notamment, il autorise la construction de maisons particulières in locis publicis, permettant ainsi d'empiéter sur les terrains publics (B.A. XV-1-1 p. 803, cité par Rouche,

15. "[...] Aedificia ipsa templorum, quae in civitatibus vel oppidis vel extra oppida sunt, ad usum publicum vindicentur; arae locis omnibus destruantur; omniaque templa in possessionibus nostris ad usus commodos transferantur; domini destruere cogantur. "(C.T. XVI-10-19).

16. " [... Eorum fana, templa, delubra si quia etiam nunc restant integra, praecepto magistratuum destrui, conlocationeque venerandae christianae religionis signi expiari praecipimus [...]. , (C.T. XVI-10-25). op. cit., p. 269). Nous avons effectivement noté place Esquirol l'installation d'habitats, peu denses au demeurant, autour du podium du temple et sur le cardo longeant le portique.

Néanmoins le Bréviaire renouvelait l'interdiction faite aux clercs de détruire les édifices publics pour réparer des églises (en référence à C.T., Nov., Valentinien XXXV (452), cité par Rouche, ibid., p. 270).

Or, le respect des notables toulousains à l'égard de la législation impériale, si obsolète soit-clle, est illustré par un passage de la Passio Sancti Saturnini. L'évêque Exupère, qui souhaite transférer le corps de Saturnin de l'ancienne "basilicula" en bois à la nouvelle "basilica pulchra et speciosa " (actuelle basilique Saint-Sernin) (Bondartchouk, 1994), dont l'évêque Silve avait commencé la construction dans le dernier quart du IV"s. (Labrousse, 1968, p. 543 sq.) et que lui-même venait d'achever, fait appel aux empereurs, sans doute Honorius et Arcadius, entre 395 et 408.

En effet, la loi réglemente sévèrement le transport des corps; aussi l'évêque demande-t-il un rescrit impérial permettant de le faire en toute légalité ${ }^{17}$.

Il procède au transfert dès l'obtention du rescrit. Exupère, dont nous savons qu'il était évêque de la ville entre 405 et 412 , et sans doute au-delà, est un personnage de grande envergure, correspondant avec les plus hautes autorités civiles et religieuses, attentif aux problèmes sociaux et politiques de la cité (Labrousse, 1968, p. 566). C'est peut-être ce notable qui a permis, au début du V's., la destruction du Capitole et la restructuration de la partie nord du forum par le biais des autorités municipales, préfigurant ainsi le rôle supposé de Basilius à Aix (Guild et al., 1985, p. 18).

I.e remaniement du centre monumental est peut-être aussi à envisager dans le cadre de l'installation de la cour wisigothique à partir de 418 , ce qui induit un déplacement du centre du pouvoir, peut-être vers les bords de la Garonne dans le secteur de l'ancien hôpital Larrey (Collectif, 1995, p. 61 sq.), ajoutant une déchéance politique à la déchéance religieuse de l'ancien forum, amorcée dans le courant du IV $s$.

17. "[...] Religiosis Imperatoribus precem detulit, ac sine mora ulla quod tam pie poposcerat impretravit, ut translatas ad basilicam omni studio praeparatam sancti vin reliquias $[. ..] .,(\$ 6)$. 


\section{LA CONSTRUCTION D'UNE BASILICA AU VI ${ }^{\mathrm{e}} \mathrm{s}$.}

La christianisation du temple en 567 pose plusicurs problèmes ${ }^{18}$. D'une part, cela sous-entend une période d'abandon de près de deux sic̀cles, ce qui paraît courant à travers les exemples connus de réutilisation de temples en églises en Gaule (Young, 1988, p. 219 sq.). Durant cette période, le temple ruiné demeure en élévation, ou tout du moins la structure du podium perdure. Le temple était d'ailleurs protégé en théorie par une disposition du Bréviaire d'Alaric inspirée du Code théodosien (X-19-14) interdisant de creuser dans les fondations d'édifices anciens pour y chercher de la pierre, du marbre ou du métal et de s'emparer de pierres nobles (B.A., X-11-1, p. 560, cité par M. Rouche, 1979 , p. 192 et 568) ${ }^{19}$.

L'instigatcur du templum ou de la basilica qui vient couronner les ruines du temple est un fonctionnaire mérovingien d'ethnie barbare étranger au clergé de la ville (Reydellet, 1994, II-8). Peut-être faut-il y voir le signe d'une continuation de l'appartenance de la zone au domaine public, du fait de l'absorption des biens fonciers des municipalités par le fisc royal, et notamment des édifices publics (Bréviaire d'Alaric, en référence à C.T. III-IV, cité par Rouche, op. cit., p. 262).

En tout cas, le templum construit par I aunebode et sa femme, même s'il subsista à travers le Moyen Âge sous l'appcllation ecclesia sancti Petri sancti Geraldique, ne fut jamais un édifice majeur de Toulouse; le souvenir de sa fondation et de sa fonction commémorative du lieu du martyre de Saturnin s'effaça rapidement, cet oubli impliquant celui de la localisation du Capitole (Boudartchouk, Arramond, 1993).

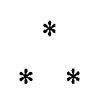

18. Il serait fastidieux d'aborder ici la problématique de la transformation des temples païens en églises chrétiennes en milieu urbain. On se référera pour cola à plusieurs articles de fond : Deichmann, 1939; Duval, 1971 ; Garcia-Moreno, 1978; Young, 1988; Vaes, 1989. Concernant la christianisation des anciens (apitoles, of. Boudartchouk, Arramond (1993, p. 20-21) où sont répertoriés une dizaine de cas. Ces inventaires montrent que tous les schémas sont possibles : abandon total du temple païen, réutilisation intégrale ou partielle de celui-ci en tenant compte ou non de sa structure générale, immédiatement après sa désaffection ou plusieurs siècles après...

19. " (hicumque melallum dicens sub alienis aedificiis quaelibet saxa vel marmora effodienda crediderit, ut per eos fundamentorum firmilas incipiat vacillare, his inquisitionis huius licentiam denegamus, ne, dum nobiliores lapides se quaerere adserunt, aut vendere aut subvertere aliena fundamenta praesumant."
La découverte du Capitolium de Tolosa pose incontestablement autant de problèmes qu'elle en résout.

Tout d'abord, le plan de l'édifice n'a été que partiellement reconnu, les cellae en particulier restent à fouiller, alors que leur emprise hors de la halle du XIX s. laisse cspérer une meilleure conservation que celle du pronaos. Ceci permettrait en outre de préciser les modalités de l'implantation de l'église Saint-Pierre-Saint-Géraud sur leur emplacement. De même, les superstructures du sanctuaire restent peu connues dans le détail ; tout au plus peut-on restituer le plan d'un temple corinthien octostyle pseudo-périptère. Ia façon dont le sanctuaire s'intègre dans le complexe du forum doit, elle aussi, ĉtre précisée.

D'un point de vue chronologique, de nombreuses zones d'ombre subsistent. Il a ainsi été impossible de déterminer si un édifice existait antérieurement au Capitole, comme cela semble être le cas à Narbonne, le niveau de sol ayant fait l'objet d'un nivellement lors de la construction. De même, les modalités précises de l'utilisation du temple demeurent inconnues, le seul jalon étant fourni par l'application probable de l'édit de Dèce sur le site en 250 de notre ère.

Enfin les phases de destruction et les réaménagements postérieurs à la fin du $\mathrm{V}^{*} \mathrm{~s}$. de notre ère nous échappent presque entièrement. Ces lacunes, pour importantes qu'elles soient, ne doivent pas masquer unc série d'acquis topographiques et chronologiques qui renouvellent sensiblement notre connaissance de la ville antique. Le caractère monumental de l'édifice (43x $27 \mathrm{~m}$ au sol pour environ $25 \mathrm{~m}$ de haut) implique la puissance et la prospérité du chef-lieu de cité des Tolosates, que laissait entrevoir l'enceinte du Irr $s$. De même le forum dont on entrevoit l'emprise parait de dimensions importantes, à l'échelle d'une cité dont la superficie intra-muros dépasse 90 ha.

La présence en Narbonnaise d'un sanctuaire consacré au culte de la triade capitoline, qui représente sans doute la forme la plus élaborée de religion d'État, traduit bien la "romanité " de Toulouse qui a dû atteindre sa plénitude avec le statut de colonic sous Néron ou les Flaviens. C'est alors seulement que la cité aurait entrepris l'édification d'un centre monumental pleinement structuré, selon le schéma désormais classique pour la Gaule. Néanmoins cette monumentalisation se réalise à l'intérieur d'une trame 
urbaine qu'il est possible de faire remonter à l'époque d'Auguste/Tibère/Caligula ${ }^{20}$.

Les fouilles du parking Esquirol fournissent aussi d'autres éléments importants concernant la cité durant l'Antiquité tardive. Notamment, la destruction du temple et le réaménagement de l'area correspondent chronologiquement au triomphe définitif du christianisme sur un plan local (Exupère) suivi par l'installation des Wisigoths consécutive au foxdus de 418. Dans cette optique, le Capitole de Toulouse aurait été le point d'orgue de la cité dans sa plénitude, conséquence de l'obtention du plus haut statut juridique, avant d'être délaissé lors de l'abandon des cultes civiques, puis de la création du royaume wisigoth. Au V's. les enjeux politiques et religieux paraissent se fixer ailleurs, la vocation économique de l'ancien centre urbain a pu traverser le Haut Moyen Âge pour aboutir au marché de la Pierre attesté au XII* s.

Enfin et d'un point de vue plus général, les découvertes du parking Esquirol posent à nouveau le problème de la place occupéc par le culte de la triade capitoline aux côtés du culte impérial, en Gaule et plus spécialement en Narbonnaise ${ }^{21}$.
20. Adversus de Filippo (1993b, p. 202) qui situe la construction du forum en même temps que la réalisation de la trame urbainc et de l'enceinte. Lors des fouilles du parking Esquirol on a pu observer clairement que les fondations du portique du temple perforaient les niveaux de voirie du cardo oriental datant de la première moitié du $\mathrm{I}^{\mathrm{ct}}$ s., ces derniers recourrant l'égout axial daté par archéomagnétisme des règnes d'Auguste ou de Tibère.
21. Remerciements à M. Vidal, ainsi que P. Bonnassie, D. Cazes, M.-G. Colin, M. Fincker, B. Marty; J-M. Pailler, R. Sablayrolles, D. Schaad, J.- L. Schenck, P. Sillières et A. Vernhet. 


\section{BIBLIOGRAPHIE}

ARANEgui-Gasco C.

1991 : Un templo republicano en el centro civico Saguntino, in : Templos romanos de Hispania, Cuadernos de Arquitectura Romana, I, p. 67-82.

ARBULO J.-R. DE

1991: El templo del foro de Ampurias y la evolucion de los foros republicanos, in : Templos romanos de Hispania, Cuadernos de Arquitectura Romana, I, p. 11-37.

ARRAMOND J.-CH., BOUdARTCHOUK J.-L.

1993 : Travaux et recherches archéologiques de terrain. Toulouse, parking Esquirol, Bilan Scientifique de la Région MidiPyrénées, 1992, Toulouse, Service régional de l'Archéologie, p. 73.

BACCRABÈRE G.

1964 : L'aqueduc de la Reine Pédauque à Toulouse, Mémoires de la Société Archéologique du Midi de la France, p. 95-96.

1977 : Étude de Toulouse romaine, suppl. au Bulletin de littérature ecclésiastique, Chronique $n^{\circ} 3$, Institut catholique de Toulouse.

1984 : Habitat, alimentation et évacuation des eaux à Toulouse dans l'Antiquité, Revue de l'Académie des Sciences, Inscriptions et Belles-Lettres de Toulouse, V, 146, p. 126-133.

Badie A., Sablayroli.es R., Schenck J.-L. 1994 : Le temple du forum et le monument à enceinte circulaire, Bordeaux, éd. Fédération Aquitania.

\section{BALTY P.}

1993 : Le centre civique des villes romaines et ses espaces politiques et administratifs, in : La ciudad en el mundo romano -I- Ponencias, Actes du XIV"Congresso internacional de Arqueologia clasica, Tarragona 5-11 sept. 1993, p. 21 sq.
BARTON I.

1982 : Capitoline temples in Italy and the provincies, especially Africa, Aufstieg und Niedergang der römischen Welt : Geschichte und Kultur Roms im Spiegel der neueren Froschung, II, 12-1, p. 259342.

Bedon R., Chevalier R., Pinon P.

1988 : Architecture et urbanisme en Gaule romaine, t. I et II, Paris, Errance.

\section{BIANCHI U.}

1950 : Disegno storico del culto capitolino nell' Italia e nelle provincie dell' Imperio, in : Atti della Academia nazionale dei Lincei, série VIII, vol. 2, fasc. 7, p. 349-414, Rome.

1975 : I capitolia, in : Atti del Convegno internazionale per il centenario della dedicazione del capitolium, Brescia, 27 30 sept. 1973, vol. I, p. 63-76.

BL.UTSTEIN-LATREMOLIËRE E.

1991 : Les places capitolines d'Espagne, Mélanges de la Casa de Velasquez, XXVII-1, p. 43-64.

BOUDARTCHOUK J.-L.

1994 : Le locus de la première sépulture de l'évêque Saturnin de Toulouse : un état de la question, Mémoires de la Société Archéologique du Midi de la France, LIV, p. 59-70.

Boudartchouk J.-L., ARRamond J.-Ch. 1993 : Le souvenir du Capitolium de Toulouse à travers les sources de l'Antiquité tardive et du Moyen Âge. État de la question et perspectives nouvelles, Archéologie du Midi médiéval, XI, p. 3- 39.

BRIDEL.

1982 : Le sanctuaire du Cigognier à Avenches, Aventicum, III, Lausanne.

BROUQUIER-REDDÉ V.

1992 : Temples et cultes de Tripolitaine,
Études d'Antiquités africaines, Paris, CNRS Éditions.

Brousse J.-R. DE

1932 : Les derniers restes de l'église SaintGéraud place Esquirol, L'Auta, 52, p. 146-152.

\section{Cagiano de Azevedo M.}

1940 : I capitolia dell'impero romano, in : Atti della Pontificia Accademia Romana di Archeologia, serie III, memorie vol. V, Rome, p. 1-76.

\section{Castagnoli F.}

1959 : Capitolium, in : Enciclopedia dell' arte antica, II, p. 326-330.

1984 : Il tiempo romano : questioni di terminologia e de tipologia, Papers of the British School at Rome, LII, p. 3-20.

\section{CASTAN A}

1869 : Le Capitole de Vesontio et les Capitoles provinciaux du monde romain, Mémoires de la Société d'Émulation du Doubs, séances des 19 déc. 1867 et 23 mars 1868 , p. 201 235.

1886 : Les Capitoles provinciaux du monde romain, Mémoires de la Société d'Émulation du Doubs, $5^{\mathrm{c}}$ série, $10^{\mathrm{c}}$ vol., année 1885, p. 169-404.

\section{CAVAlieri-Manasse G.}

1990 : Il foro di Verona : recenti indagini, in : La Città nell'Italia settentrionale in età romana, coll. de l’École française de Rome, 130, p. 579-616.

\section{Cazes D.}

1988 : La ville dans ses murs, in : Palladia Tolosa, Catalogue d'exposition du Musée Saint-Raymond, Toulouse 1988, p. 61 sq.

\section{Coarelli F., Cajanto I.}

1981: L'area sacra di Largo Argentina, Rome. 
COILECTIF

1990 : Stadtbild und Ideologie, Actes du Colloque de Madrid, 19-23 oct. 1987, Munich.

1991: L'espace sacrificiel dans les civilisations méditerranéennes de l'Antiquité, Publication de la bibliothèque Salomon Reinach, Univ. Lumière-Lyon 2.

1995 : Archéologie toulousaine. Antiquité et Haut Moyen Âge. Découvertes récentes : 1988-1995, Catalogue du Musée Saint-Raymond, Toulouse 1995.

\section{Darember(; Ch., Saglio E.}

1887 : «Capitolium», in : Dictionnaire des Antiquités grecques et romaines (DAGR), Paris, Hachette, p. 901-906.

\section{Deichmann F.-W.}

1939 : Frühchristliche Kirchen in Antiken Heiligtümern, Jahrbuch des Deutschen Archäologischen Instituts, 54, p. 105136.

\section{DUBY G. (ÉD.)}

1989 : Histoire de la France urbaine, I, Paris.

Duval. N.

1971 : Église et temple en Afrique du Nord, Bulletin Archéologique du Comité des Travaux Historiques et Scientifiques, nouvelle série, fasc. 7, p. 265-296.

\section{ÉTIENNE R.}

1985 : Un complexe monumental du culte impérial à Avenches, Bulletin de l'Association Pro Aventico, 29, p. 5-26.

\section{FEROTIN M.}

1912 : Liber mozarabicus sacramentorum, Paris.

\section{FÉVRIER P.-A}

1975 : À propos du Capitole de Brescia, sur quelques exemples africains, in : Atti del Convegno internazionale per il centenario della dedicazione del capitolium, Brescia, 27-30 sept. 1973, p. 129-139.

\section{FILIPPO R. DE}

1993a : Travaux et recherches archéologiques de terrain. Toulouse, ligne $\mathrm{A}$ du métro, station Esquirol, Bilan Scientifique de la Région MidiPyrénées, 1992, Toulouse, Service régional de l'Archéologie, p. 69 et 70.

1993b : Nouvelle définition de l'enceinte romaine de Toulouse, Gallia, 50, p. 181 204.

\section{FISHWICK D.}

1992 : Un don de statues d'argent à Narbo Martius, Comptes rendus de l'Académie des Inscriptions et Belles-Lettres, 2, p. 381-420.

GarCIA-Moreno L.-A.

1978 : La cristianizacion de la topografia de las ciudades de la peninsula iberica durante la antiquedad tardia, Archivo Español de Arqeologia, 135-138, p. 311321.

\section{Gayraud M.}

1981 : Narbonne antique des origines à la fin du III siècle, RAN, suppl. 8, Paris.

\section{GILIES H.}

1969 : Les coutumes de Toulouse et leur premier commentaire, Académie de Législation, 6 série, t. V, Toulouse, p. 23-39.

GRENIER A.

1958 : Manuel d'archéologie gallo-romaine, III, Paris, Picard.

Gros P.

1976 : Aurea templa. Recherches sur l'architecture religieuse de Rome à l'époque d'Auguste, Bibliothèques des Écoles françaises d'Athènes et de Rome (Collection des), Paris, 231.

1986 : Sanctuaires traditionnels, Capitoles et temples dynastiques : ruptures et continuités dans le fonctionnement et l'aménagement des centres religieux urbains, in : Los asentamientos ibericos ante la romanizacion, Madrid, p. 111-120.

1990a : Les étapes de l'aménagement monumental du forum : observations comparatives (Italie, Gaule narbonnaise, Tarraconaise), in : La Città nell'Italia settentrionale in età romana, coll. de l'École française de Rome, 130 , p. 2968.

1990b : Vitruve : De l'architecture, Livres III et IV, Paris, Les Belles Lettres.

1991: La France gallo-romaine, Paris.

1996 : L'architecture romaine du début du III siècle av. J.-C. à la fin du Haut-
Empire -1- Les monuments publics, Paris, Picard.

GUII.D R. GUYoN J.. RIVET L.

1985: La cathédrale et le baptistère d’Aix, in : Actes du Congrès Archéologique de France, p. 18-52.

HANLEIN-SCHÄFER H.

1985 : Veneratio Augusti, Rome.

HAUSCHILD T.

1991 : El templo romano de Evora, in :

Templos romanos de Hispania, Cuadernos de Arquitectura Romana, I, p. 107-117.

HELI.ENKEMPER H.

1975 : Architektur als Beitrag 7ur Geschischte der Colonia Ara Agrippinensorum, Aufstieg und Niedergang der römischen Welt : Geschichte und Kultur Roms im Spiegel der neueren Froschung, II-4, p. 783.

HINZ H.

1975 : Colonia Ulpia Traiana, Aufstieg und Niedergang der römischen Welt : Geschichte und Kultur Roms im Spiegel der neueren Froschung, II-4, p. 803809.

HOFMANN B.

1975 : Les matériaux de construction en terre cuite, Dossiers de l'Archéologie, 9, p. $111-120$.

JIMENEZ-SALVADOR J.-L.

1985 : Informe sobre la excavacion [...] en el templo romano de la calle Claudio Marcelo en Cordoba, in : Annuario Arqueologico de Andalucia, II, p. 394398.

1991 : El templo romano de la calle Claudio Marcelo en Cordoba, in : Templos romanos de Hispania, Cuadernos de Arquitectura Romana, I, p. 119-132.

\section{LABROUSSE M.}

1968 : Toulouse antique des origines à l'établissement des Wisigoths, Bibliothèques des Écoles françaises d'Athènes et de Rome (Collection des), Paris.

LANES M.

1903 : Découvertes place Rouaix, Bulletin 
de la Société Archéologique du Midi de la France, p. 223-224 et 227-228.

LASFARGiUES J., LE GI.AY M.

1980 : Découverte d'un sanctuaire municipal du culte impérial à Lyon, Comptes rendus de l'Académie des Inscriptions et Belles-Lettres, séance du 30 mai 1980, p. 394-414.

\section{LEPELLEY C}

1979 : Les cités de l'Afrique romaine au Bas-Empire, I, Paris.

LIMOUZIN-LAMOTHE: R.

1932 : La commune de Toulouse (1120) 1249) et les sources de son histoire, Toulouse, éd. Privat, Paris, éd. Didier.

MALAFOSSE M.-J.

1893 : Découvertes survenues à la Place de la Pierre, Bulletin de la Société Archéologique du Midi de la France, séance du 11 avril 1893, p. 70.

MANDY B.

1983 : Le quartier antique du Verbe Incarné, Dossiers Histoire et Archéologie. 78, p. 23-26.

Manino L.

1969 : Cryptoporticus, in : Institut international d'Études Ligures, Hommage à F. Benoit, Revue d'Études Ligures, XXXV' année, n"' 1-3, janv.-sept. 1969 , p. 287-303.

Mar R., ARbulo J.-R. DE

1985 : El templo del foro romano de Ampurias, Investigaciun y Ciencia, 105, juin 1985, p. 68-77.

1990 : El foro de Ampurias y las transformaciones Augusteas de los foros de la Tarraconense, in : Stadtbild und Ideologie, Actes du Colloque de Madrid, 19-23 oct. 1987, Munich, p. 145-164.

MARTIN J.-P.

1991 : Société et religions dans les provinces romaines d'Europe centrale et occidentale, Regard sur l'Histoire, Paris, Sedes.

\section{Martin-Chabot E.}

1918: La tradition capitoline à Toulouse à la fin du XIII" siècle, Annales du Midi, XXX, p. 345-354.
MATIJASIC R.

1990 : Breve nota sui templi forensi di Nesazio e Pola, in : La Città nell'ltalia settentrionale in età romana. coll. de l'École française de Rome, 130, p. 6.356.50 .

MII.NE G.

1992 : From Roman Basilica to Medieval Market, Londres.

Mol.et H., ARramoni) J.-C., BOUDARTCHOUK J.-L.

1993 : L’ancienne église Saint-Pierre et Saint-Géraud de la Pierre à Toulouse, Mémoires de la Société Archéologique du Midi de la France, LIII, p. 145-167.

PAILLER J.-M.

1988 : Domitien et la cité de Pallas. Un tournant dans I'histoire de Toulouse antique, Pallas, p. 99-109.

\section{Perret V.}

1956 : Le Capitole de Narbonne, Gallia, XIV, I. p. 1-22.

Prifur J.

1982 : Les arcs monumentaux dans les Alpes occidentales : Aoste, Suse, Aix-lesBains. Aufstieg und Niedergang der römischen Welt : Geschichte und Kultur Roms im Spiegel der neueren Froschung, II, 12-1, p. 442-475.

1988: Les animaux sacrés dans l'Antiquité, éd. Ouest-France.

REydellet M.

1994 : Venance Fortunat, Pò̀mes, I, Paris, Société des Belles-Lettres.

Romanhil. P.

s. d. : Topografia e archeologia dell Africa romana, in : Enciclopedia classica, sect. III, vol. X. t. VII, p. 116-130 et tabl. 83-94.

RouCHE M.

1979 : L'Aquitaine des Wisigoths aux Arabes. Naissance d'une région, Paris. EHESS.

SAPËNE. B.

1933 : Rapport sur les fouilles de SaintBertrand-de-Comminges, année 1932, Toulouse.
TolD) M.

1985 : Forum and Capitolium in the early Empire, in : Roman urban topography in Britain and the Western Empire, Londres, éd. F. Grew and B. Hobley. p. 56-66.

TRUNK M.

1991 : Römische Temple in den Rhein und westlichen Donauprovinzen, Augst, p. 23-251.

VAES J.

1989 : Nova construere sed amplius vetusta servare. La réutilisation chrétienne d'édifices antiques en Italie, in : Actes du XI Congrès international d'Archéologie chrétienne, I, coll. de l'École française de Rome, 123, p. 299 321.

VETTERS $\mathrm{H}$.

1977 : Virunum, Aufstieg und Niedergang der römischen Welt : Geschichte und Kultur Roms im Spiegel der netreren Froschung, 2-6, p. 314 sq.

VIDAL. M.

1987 : Les villes - Toulouse, in : Dix ans de recherches archéologiques en MidiPyrénées, Catalogue d'exposition du Musée Saint-Raymond, Toulouse. p. 64 sq.

VidAL. M., JaUuBERT J.

1993 : Résultats scientifiques significatifs, Bilan Scientifique de la Région MidiPyrénées, 1992, Toulouse, Service régional de l'Archéologie, p. 15 et 70.

Younci B. K.

1988 : Sacred topography and early christian churches in late antique Gaul, in : First Millenium Papers, British Archaeological Reports, International Series 401, London, p. $219 \mathrm{sq}$.

Bibliographie complémentaire et sources concernant le martyre de Saturnin de Toulouse, in : Boudartchouk, Arramond, 1993. 